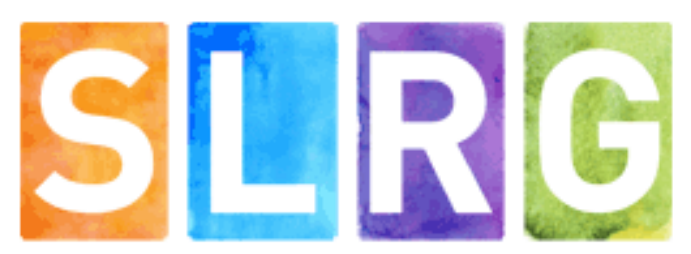

Sustainable Lifestyles Research Group

\title{
Living up to expectations
}

Estimating direct and indirect rebound effects for UK households

by

Mona Chitnis ${ }^{\star}$ and Steve Sorrell ${ }^{* *}$

* Surrey Energy Economics Centre (SEEC), School of Economics, University of Surrey, UK

** Sussex Energy Group, Science Policy Research Unit (SPRU), University of Sussex, UK

\section{SLRG Working Paper Series \\ 15-01}

ISSN: $2050-4446$

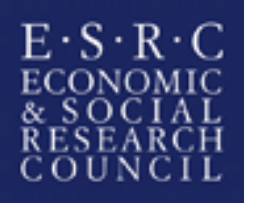




\section{SLRE \\ Sustainable Lifestyles Research Group}

The Sustainable Lifestyles Research Group (SLRG) is a multi-centre research network collaborating to further understanding of the opportunities and constraints on sustainable living in the UK. The SLRG is coordinated from the University of Surrey, and brings together project teams from Surrey's Centre for Environmental Strategy (CES) and Departments of Sociology and Psychology. It also includes teams at other internationally acclaimed research centres: the University of Sussex's Science Policy Research Unit; the Institute for Fiscal Studies; the University of Edinburgh; the University of Bath; and Brunel University.

SLRG is directed by Professor Tim Jackson, Professor of Sustainable Development at the University of Surrey, with Professor Andy Stirling of the University of Sussex as deputy director. The network is coordinated by lan Christie, research fellow at CES.

Funded by the Department for Environment, Food and Rural Affairs (Defra), the Scottish Government and the Economic and Social Research Council (ESRC), SLRG builds on the pathbreaking research of the University of Surrey's previous Research, ESRC-funded programme RESOLVE - Research on values, lifestyles and environment, also directed by Professor Tim Jackson. SLRG works in partnership with its sister programme the Sustainable Practices Research Group (SPRG), funded by the ESRC and coordinated by Professor Dale Southerton at the University of Manchester.

SLRG and SPRG aim to document and analyse the complex links between lifestyles, consumption, everyday practices, values and the transition to sustainable ways of life. While SPRG focuses on particular consumption practices and technologies, SLRG's projects examine the lifestyles of households and communities and model the implications of consumption choices and values.

The working papers in this series reflect the outputs, findings and recommendations emerging from a truly inter-disciplinary research programme arranged around four thematic research strands:

Moments of transition: in-depth quantitative and qualitative research with households to understand the values, attitudes and habits informing their lifestyles, and to assess the impact of moments of major change - moving house, the arrival of the first child, and retirement - on habits and aspirations.

Community and lifestyle change: studies of sustainable lifestyle change and innovations at the level of communities, focusing on remote rural localities in Scotland and on civil society initiatives for food growing and local resilience in England.

Economic modelling of lifestyle change: studies focusing on the size and nature of rebound effects in energy use that could reduce or cancel out the gains from energy efficiency advances; and on the price responsiveness of consumption in relation to energy and sustainably produced foodstuffs.

Synthesis of research and implications for policy: workshops and papers seeking to integrate findings and concepts across the suite of SLRG and SPRG projects; and research into the relationship of research evidence on sustainable living to policy development.

For further information about our research programme or the SLRG Working Paper series please visit our website www.sustainablelifestyles.ac.uk 


\title{
SLRG Working Paper 15 -01
}

\author{
Sustainable Lifestyles Research Group \\ Centre for Environmental Strategy (D3) \\ University of Surrey \\ Guildford, GU2 7XH, UK \\ http://www.sustainablelifestyles.ac.uk
}

\section{Contact details}

Corresponding author: Steve Sorrell, Sussex Energy Group, SPRU (Science and Policy Research Unit), University of Sussex, Brighton, UK Tel. +44 (0) 1273 877067, mail: s.r.sorrell@sussex.ac.uk

\section{Acknowledgements}

The support of the Department for Environment, Food and Rural Affairs (Defra), the Economic and Social Research Council (ESRC) and the Scottish Government is gratefully acknowledged. This work is part of the research programme of SLRG - the Sustainable Lifestyles Research Group.

ISSN: 2050-4446

(C) Sustainable Lifestyles Research Group (SLRG), 2015

The views expressed in this document are those of the authors and not of the SLRG, ESRC, Defra, The Scottish Government or the University of SurreyA.bRstreasacton able efforts have been made to publish reliable data and information, but the authors and the publishers cannot assume responsibility for the validity of all ma terials. This publication and its contents may be reproduced as long as the reference 


\section{Abstract}

This study estimates the combined direct and indirect rebound effects from various types of energy efficiency improvement by UK households. In contrast to most studies of this topic, we base our estimates on cross-price elasticities and therefore capture both the income and substitution effects of energy efficiency improvements. Our approach involves estimating a household demand model to obtain price and expenditure elasticities of different goods and services, utilising a multiregional input-output model to estimate the GHG emission intensities of those goods and services, combining the two to estimate direct and indirect rebound effects, and decomposing those effects to reveal the relative contribution of different mechanisms and commodities. We estimate that the total rebound effects are $63 \%$ for measures that improve the efficiency of domestic gas use, $53 \%$ for electricity use and $46 \%$ for vehicle fuel use. The primary source of this rebound is increased consumption of the cheaper energy service (i.e. direct rebound) and this is primarily driven by substitution effects. Our results suggest that the neglect of substitution effects may have led prior research to underestimate the total rebound effect. However, we provide a number of caveats to this conclusion, as well as indicating priorities for future research.

Keywords: Rebound effects; Income and substitution effects; linear almost ideal demand system 


\section{Introduction}

'Rebound effects' is a widely used term for a variety of economic responses to improved energy efficiency. The net result of these effects is typically to increase energy consumption and greenhouse gas (GHG) emissions relative to a counterfactual baseline in which these responses do not occur. To the extent that rebound effects are neglected in policy appraisals, the energy and emissions 'saved' by such measures may be less than anticipated.

Studies of rebound effects for consumers typically focus upon the direct effects that result from increased consumption of cheaper energy services. For example, fuel-efficient cars make driving cheaper so people may drive further and/or more often (Small and Van Dender, 2007; Sorrell, 2007). But a comprehensive accounting of the global environmental impact of energy efficiency improvements must also take into account various indirect rebound effects. For example, any savings on petrol bills may be put towards increased consumption of other goods and services whose provision also involves energy use and emissions at different stages of their global supply chains (Chitnis et al., 2013; Druckman et al., 2011b). To quantify indirect rebound effects, it is necessary to combine econometric analysis of household (re)spending patterns with estimates of the energy and emissions 'embodied' within different categories of goods and services. The latter, in turn can be derived from environmentally extended, multiregional input-output models (Druckman and Jackson, 2009; Turner et al., 2007; Wiedmann et al., 2007).

Relatively few studies estimate both direct and indirect rebound effects and most of these rely upon expenditure elasticities rather than cross-price elasticities. As a result, they capture the income effects of energy efficiency improvements but not the substitution effects (Chitnis et al., 2014). To appreciate the distinction, consider a household that installs insulation and 
recovers the capital costs over ten years through lower heating bills. Since the bill savings exactly offset the capital costs, there is no increase in real income over this period so the income effect is zero. Hence, studies that focus solely upon income effects would estimate the direct and indirect rebound effects over that period to be zero as well. But since the unit cost of heating has fallen relative to that of other goods and services, the household is likely to consume more heating and fewer goods and services that are 'substitutes' to heating. At the same time, the household may consume more of other goods and services that are 'complements' to heating. The net result will be a shift in consumption patterns and hence a change in the GHG emissions associated with that consumption that may offset the original emission savings. Hence, it is possible that studies that neglect substitution will underestimate rebound effects.

This study therefore addresses the limitations of the existing literature by: a) estimating the magnitude of both direct and indirect rebound effects following the adoption of energy efficiency measures by households; b) identifying the relative contribution of income and substitution effects to these results; and c) identifying the relative contribution of individual goods and services. This is the first study to estimate these effects for UK households, as well as the first to decompose them to this level of detail.

The paper is structured as follows. Section 2 introduces the relevant concepts, highlights some methodological trade-offs and summarises the existing literature. Section 3 outlines the methodology, including the data sources used, the economic model adopted and the econometric techniques employed. Section 4 presents the results, including the estimates of direct and indirect rebound effects and the contribution of different mechanisms and commodities to those effects. Section 5 discusses the robustness of the results and highlights some implications. Section 6 concludes. 


\section{Concepts and previous work}

\subsection{Direct rebound effects}

Cost-effective energy efficiency improvements reduce the effective price of energy services such as heating and lighting, thereby encouraging increased consumption of those services that offsets the initial energy and emission savings. The marginal change in the energy $\left(q_{e}\right)$ required to provide a given quantity of energy service $\left(q_{s}\right)$ following a marginal change in energy efficiency $\left(\varepsilon=q_{s} / q_{e}\right)$ may be expressed as:

$$
\eta_{q_{e}, \varepsilon}=\frac{\partial \ln q_{e}}{\partial \ln \varepsilon}
$$

As shown by Sorrell and Dimitropoulos (2007a), this may be written as: ${ }^{1}$

$$
\eta_{q_{e}, \varepsilon}=-\eta_{q_{s}, p_{s}}-1
$$

Where $\eta_{q_{s}, p_{s}}$ is the own-price elasticity of demand for the energy service $\left(q_{s}\right)$ with respect to the energy cost of that service $\left(p_{s}=p_{e} / \varepsilon\right)$. The negative of this elasticity is commonly taken as a measure of the direct rebound effect $\left(R_{D}\right)$ (Sorrell and Dimitropoulos, 2007a):

$$
R_{D}=-\eta_{q_{s}, p_{s}}
$$

\footnotetext{
${ }^{1}$ Given $q_{e}=q_{s} / \varepsilon, q_{s}=f\left(p_{s}\right)$ and $p_{s}=p_{e} / \varepsilon$, we have: $\eta_{q_{e}, \varepsilon}=\frac{\partial q_{e}}{\partial \varepsilon} \frac{\varepsilon}{q_{e}}=\frac{\varepsilon}{q_{e}}\left[-\frac{q_{s}}{\varepsilon^{2}}+\frac{\partial q_{s}}{\partial p_{s}} \frac{\partial p_{s}}{\partial \varepsilon}\right]$

Or: $\eta_{q_{e}, \varepsilon}=\frac{\varepsilon}{q_{e}}\left[-\frac{q_{s}}{\varepsilon^{2}}-\frac{1}{\varepsilon} \frac{p_{e}}{\varepsilon^{2}} \frac{\partial q_{s}}{\partial p_{s}}\right]=\frac{q_{s}}{\varepsilon q_{e}}-\frac{p_{e}}{\varepsilon^{2} q_{e}} \frac{\partial q_{s}}{\partial p_{s}}=-1-\frac{p_{s}}{q_{s}} \frac{\partial q_{s}}{\partial p_{s}}$. So: $\eta_{q_{e}, \varepsilon}=-\eta_{q_{s}, p_{s}}-1$
} 
If the energy service is a normal good $\left(0 \geq \eta_{q_{s}, p_{s}}\right)$ there will be a positive direct rebound effect $\left(R_{D} \geq 0\right)$. This may be decomposed into a substitution effect and an income effect ${ }^{2}$ using the Slutsky equation:

$$
\eta_{q_{s}, p_{s}}=\tilde{\eta}_{q_{s}, p_{s}}-w_{s} \eta_{q_{s}, x}
$$

Where: $w_{s}$ is the share of the energy service in total household expenditure $(x) ; \eta_{q_{s}, x}$ is the expenditure elasticity of the energy service; and $\tilde{\eta}_{q_{s}, p_{s}}$ is the compensated own-price elasticity of demand for the energy service, holding utility $(u)$ constant:

$$
w_{s}=\frac{p_{s} q_{s}}{x} ; \eta_{q_{s}, x}=\frac{\partial \ln q_{s}}{\partial \ln x} ; \text { and } \tilde{\eta}_{q_{s}, p_{s}}=\left.\frac{\partial \ln q_{s}}{\partial \ln p_{s}}\right|_{u=\text { constan }}
$$

In Equation 4, $\tilde{\eta}_{q_{s}, p_{s}}$ measures the substitution effect while $-w_{s} \eta_{q_{s}, x}$ measures the income effect. These may offset or reinforce one another. Table 1 summarises the influence of these terms on the sign of the direct rebound effect.

\footnotetext{
${ }^{2}$ The former is the change in consumption that would result from the change in relative prices if real income were adjusted to keep utility constant, while the latter is the change in consumption that would result exclusively from this change in real income.
} 
Table 1 Determinants of the sign of the direct rebound effect

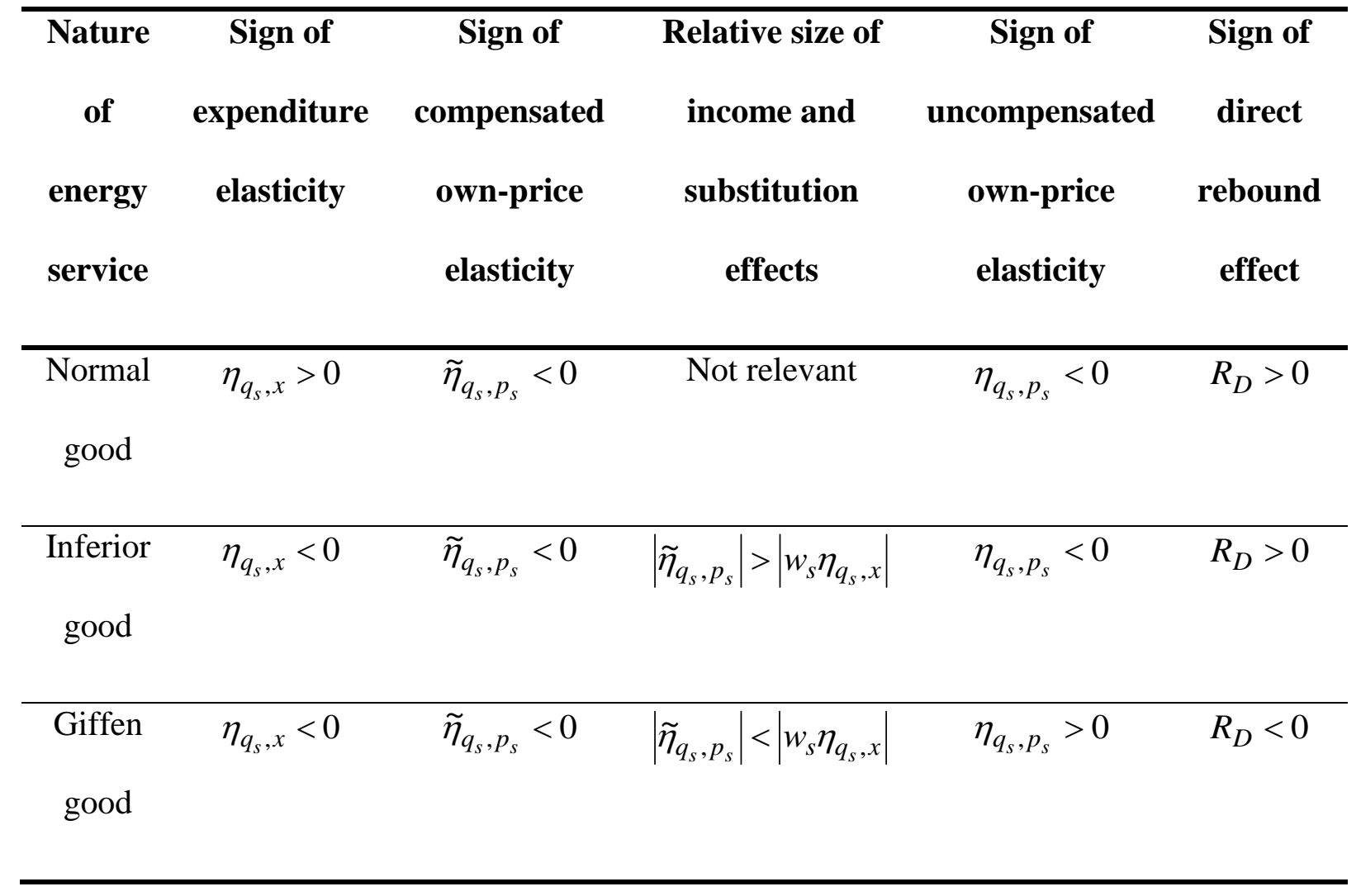

\subsection{Indirect rebound effects}

Energy efficiency improvements may also change the quantity demanded of other goods and services. These include both other energy services (e.g. heating) and other non-energy goods and services (e.g. furniture) that 'embody' the energy and emissions required to manufacture, transport and deliver them. These changes in consumption patterns will impact energy use and emissions at each stage of the relevant supply chains. From a global perspective, these changes may either offset or add to the energy and emission savings from the energy efficiency improvement depending on whether the quantity demanded of the relevant goods or service has increased or fallen. The indirect rebound effect $\left(R_{I_{i}}\right)$ from an individual commodity $(i)$ will be proportional to this change in energy and emissions, which in turn will depend upon: the energy or emissions intensity of the commodity relative to that of the 
energy service; and the elasticity of demand for the commodity with respect to the price of the energy service. The latter is defined as:

$$
\eta_{q_{j}, p_{s}}=\frac{\partial \ln q_{i}}{\partial \ln p_{s}}
$$

Again, this elasticity can be decomposed:

$$
\eta_{q_{i}, p_{s}}=\tilde{\eta}_{q_{i}, p_{s}}-w_{s} \eta_{q_{i}, x}
$$

Where: $w_{s}$ is the share of the energy service in total household expenditure; $\eta_{q_{i}, x}$ is the expenditure elasticity of commodity $i$; and $\tilde{\eta}_{q_{i}, p_{s}}$ is the compensated elasticity of demand for commodity $i$ with respect to the energy cost of the energy service:

$$
w_{s}=\frac{p_{s} q_{s}}{x} ; \eta_{q_{i}, x}=\frac{\partial \ln q_{i}}{\partial \ln x} ; \text { and } \tilde{\eta}_{q_{i}, p_{s}}=\left.\frac{\partial \ln q_{i}}{\partial \ln p_{s}}\right|_{u=\text { constant }}
$$

Again, the substitution effect for commodity $i\left(\tilde{\eta}_{q_{i}, p_{s}}\right)$ may offset or reinforce the income effect $\left(-w_{s} \eta_{q_{i}, x}\right)$. Table 2 summarises the influence of these terms on the sign of the indirect rebound effect associated with commodity $i$. Commodities that are gross complements (substitutes) to the energy service will contribute a positive (negative) indirect rebound effect, with the overall effect being given by the sum of these over all commodities $\left(R_{I}=\sum_{i} R_{I_{i}}\right)$. 
Table 2 Determinants of the sign of the indirect rebound effect for commodity $j$

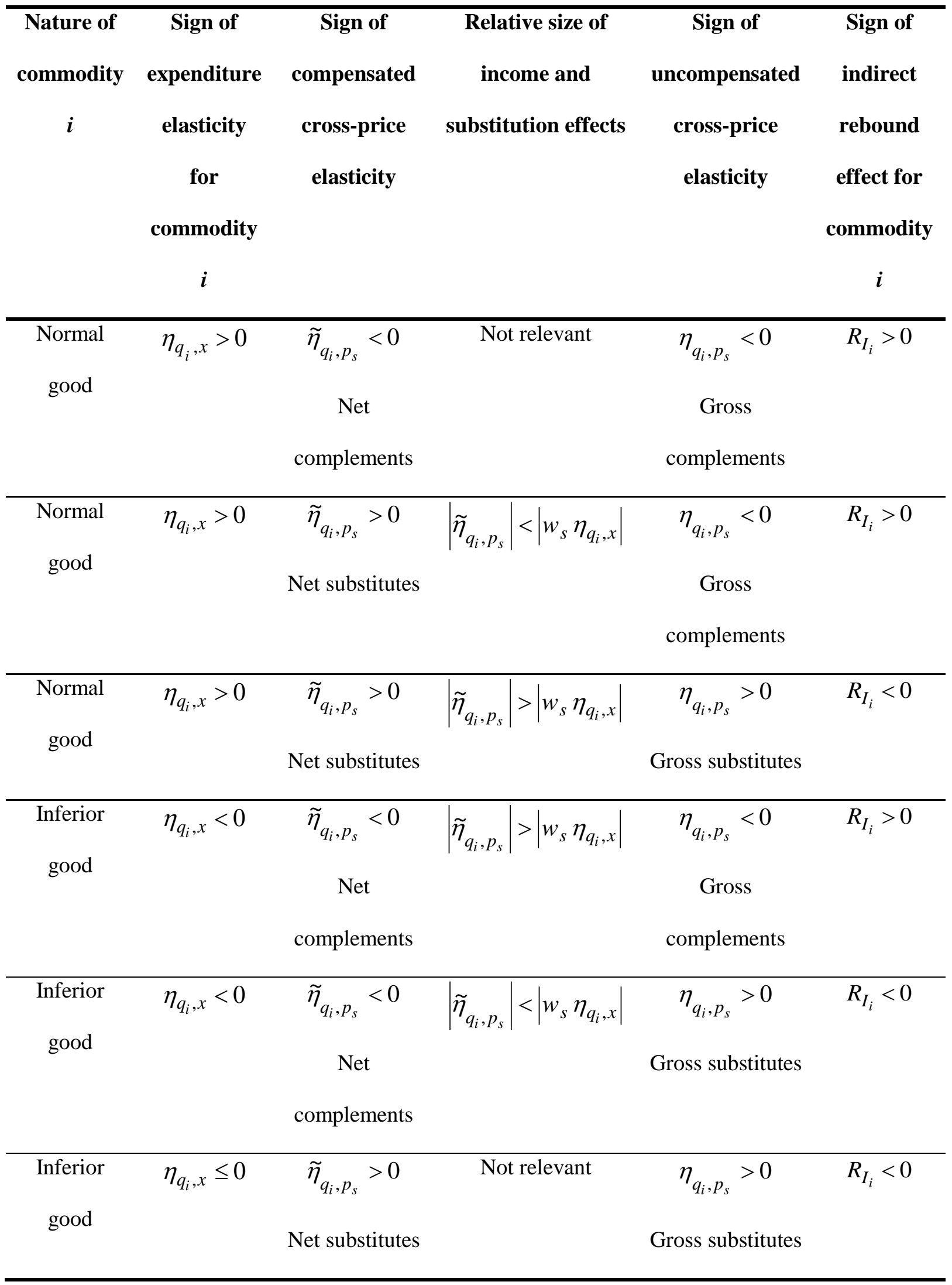




\subsection{Trade-offs in estimating direct and indirect rebound effects}

To estimate direct and indirect rebound effects we need the own- and cross-price elasticities for the relevant energy service. This requires the estimation of a household demand model namely, a system of $n$ equations representing household demand for $n$ commodities as a function of total expenditure, commodity prices and other variables, with one of these commodities being the energy service $(s)$.

A growing number of studies estimate own-price elasticities for individual energy services $\left(\eta_{q_{s}, p_{s}}\right)$, but to our knowledge no study has estimated cross price elasticities $\left(\eta_{q_{j}, p_{s}}\right)$ owing the difficulties of specifying energy services as a 'commodity' within a household demand model (Sorrell, 2010). Since energy services are produced from a combination of energy commodities (e.g. gas) and durable goods (e.g. boilers), specifying their energy cost $\left(p_{s}\right)$ and quantity demanded $\left(q_{s}\right)$ involves combining data on energy commodity purchases with additional data on the ownership and energy efficiency of the relevant durables (Conrad and Schröder, 1991). Since this data may not be available, a simpler alternative is to estimate a model for purchased commodities ( $i$ ) and to simulate energy efficiency improvements by a reduction in the price of the relevant energy commodities (l) (e.g. 2007). So, for example, more efficient boilers may be simulated by a reduction in the unit price of natural gas $\left(p_{l}\right)$, since both will reduce the energy cost of heating $\left(p_{s}\right)$. Elasticities may then be estimated with respect to energy commodity prices $\left(p_{l}\right)$, rather than energy service prices $\left(p_{s}\right)$ and used to estimate both direct and indirect rebound effects. This approach is simpler to implement but, as discussed below, may potentially lead to biased estimates of rebound effects. 
It is common to formulate household demand models in terms of expenditures $\left(x_{i}\right)$ rather than quantity demanded $\left(q_{i}\right)$ since expenditures are easier to measure. The following relationships may be derived:

$$
\begin{aligned}
& \eta_{x_{i}, p_{i}}=1+\eta_{q_{i}, p_{i}} ; \tilde{\eta}_{x_{i}, p_{i}}=1+\tilde{\eta}_{q_{i}, p_{j}} \\
& \eta_{x_{i}, p_{j}}=\eta_{q_{i}, p_{j}} ; \tilde{\eta}_{x_{i}, p_{j}}=\tilde{\eta}_{q_{i}, p_{j}} \\
& \eta_{x_{i}, x}=\eta_{q_{i}, x}
\end{aligned}
$$

Household demand models can be estimated from pooled cross-sectional data on household expenditures and commodity prices. But the number of coefficients to be estimated limits the degrees of freedom ${ }^{3}$, with the result that expenditures need to be aggregated into a limited number of commodity groups. For the same reason, such models provide limited scope for including covariates and typically require restrictions to be imposed upon the parameter values to increase the degrees of freedom. A common strategy is to assume separability of preferences between aggregate commodity groups such as food and transport, implying that decisions on how much to spend on one group (e.g. transport) are separate from decisions on how to allocate this expenditure between the goods and services within that group (e.g. bus,

\footnotetext{
${ }^{3}$ For example, suppose the demand equations took the form: $\ln q_{i}=\alpha_{i}+\eta_{i} \ln x+\sum_{j=1, n} \varepsilon_{i j} \ln p_{j}$; where is $\eta_{i}$ is the expenditure elasticity for commodity $i$ and $\varepsilon_{i j}$ are the price elasticities. In this system of $n$ equations there are $n$ intercepts $\left(\alpha_{1}, \alpha_{2} \ldots . \alpha_{n}\right), n$ expenditure elasticities $\left(\eta_{1}, \eta_{2} \ldots \eta_{n}\right)$ and $n^{2}$ price elasticities $\left(\varepsilon_{i j} i, j=1, \ldots n\right)$, leading to a total of $n(2+n)$ coefficients. So for example, if there were ten commodity groups $(n=10)$ there would be 120 coefficients to estimate, implying the need for long time series.
} 
car or train travel) (Deaton and Muellbaeur, 1980). ${ }^{4}$ This is a restrictive assumption, but it can work reasonably well if the categories are well chosen

An alternative approach is to use cross-sectional data on household expenditure to estimate Engel curves for each commodity group - indicating how expenditure on each commodity varies with total expenditure (Deaton and Muellbaeur, 1980). Engel curves allow expenditure elasticities to be estimated but not price elasticities - since the data provides no variation in commodity prices. As a result, they only allow the income effects of energy efficiency improvements to be estimated and not the substitution effects. However, Engel curves are simpler to estimate than full household demand models and permit the disaggregation of household expenditure into a larger number of commodity groups. Since there are typically more degrees of freedom, they also make it easier to include covariates and require fewer restrictions. The choice of methodological approach therefore involves some trade-offs and will depend upon the objectives of the study (Sorrell, 2010). We estimate a full household demand model in what follows, because we are particularly interested in the relative size of income and substitution effects.

\subsection{Previous work}

Tables 3 and 4 classify the limited number of studies that estimate both direct and indirect rebound effects for households - with those in Table 3 using expenditure elasticities (income effects) and those in Table 4 using cross-price elasticities (income and substitution effects). While most studies focus upon improved energy efficiency in electricity, heating or car

\footnotetext{
4 'Weak separability' implies that the marginal rate of substitution between commodities in one group is independent of the quantities of other commodities in other groups. This allows the demand for commodities within a group to be written solely as a function of the expenditure on the group and the prices of commodities within the group, with the prices of other commodities only affecting the group expenditure and not the allocation of expenditure within the group.
} 
travel, others examine 'sufficiency' measures such as reducing car travel or food waste. ${ }^{5}$ Different studies estimate rebound effects in energy, carbon and GHG terms, but no study estimates and compares all three. This diversity, combined with the methodological limitations of each study (Sorrell, 2010) makes it difficult to draw robust conclusions.

${ }^{5}$ Since sufficiency measures do not change the effective price of the energy service, there are no associated substitution effects. 
Table 3: Studies estimating combined direct and indirect rebound effects for households -income effects only

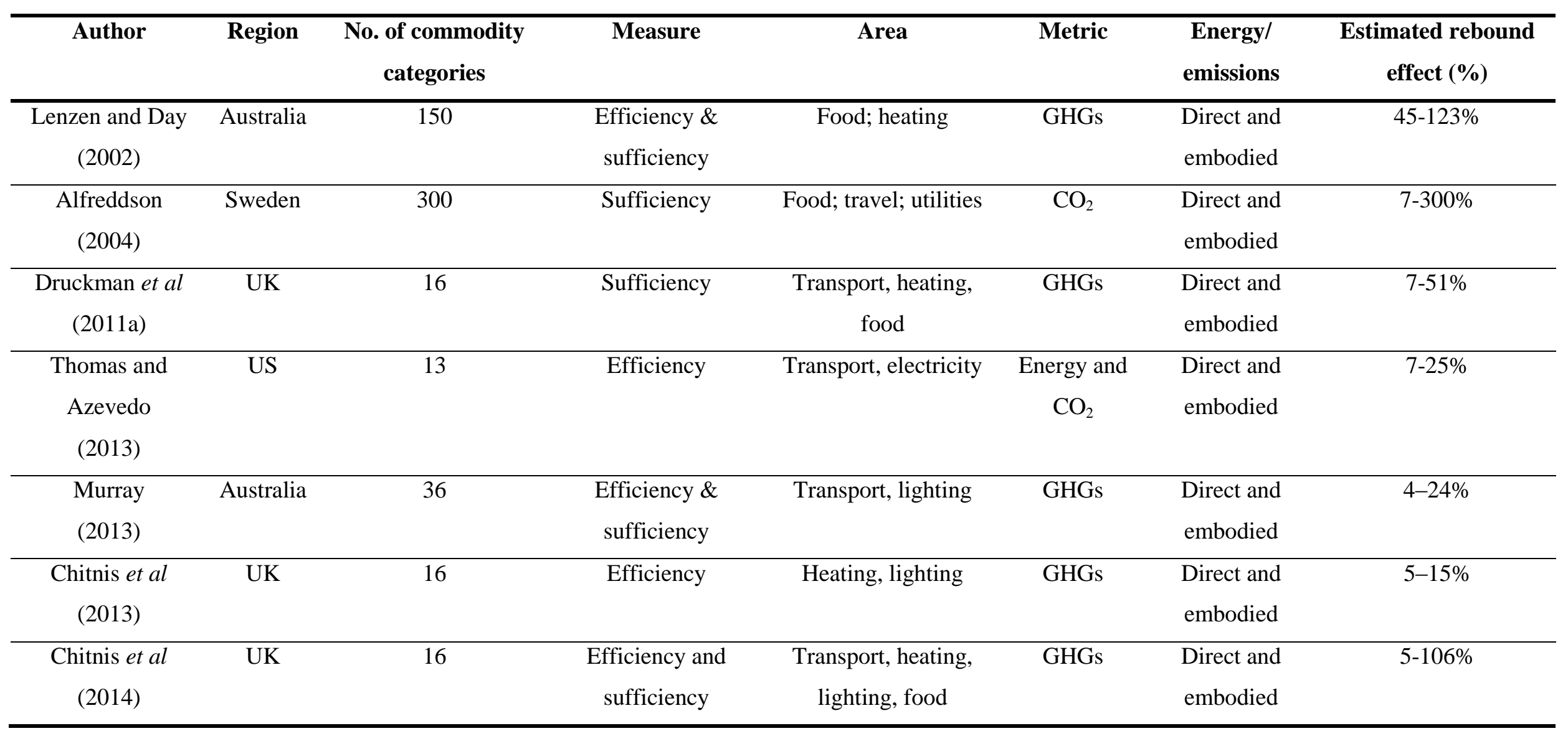


Table 4: Studies estimating combined direct and indirect rebound effects for households - income and substitution effects

\begin{tabular}{|c|c|c|c|c|c|c|c|}
\hline Author & Region & $\begin{array}{l}\text { No. of commodity } \\
\text { categories }\end{array}$ & Measure & Area & Metric & $\begin{array}{l}\text { Energy/ } \\
\text { emissions }\end{array}$ & $\begin{array}{c}\text { Estimated rebound } \\
\text { effect }(\%)\end{array}$ \\
\hline $\begin{array}{c}\text { Brannlund et al } \\
\text { (2007) }\end{array}$ & Sweden & 13 & Efficiency & Transport; utilities & $\mathrm{CO}_{2}$ & $\begin{array}{l}\text { Direct and } \\
\text { embodied }\end{array}$ & $120-175 \%$ \\
\hline Mizobuchi (2008) & Japan & 13 & Efficiency & Transport; utilities & $\mathrm{CO}_{2}$ & $\begin{array}{l}\text { Direct and } \\
\text { embodied }\end{array}$ & $12-38 \%$ \\
\hline Lin et al (2013) & China & 10 & Efficiency & Transport; utilities & $\mathrm{CO}_{2}$ & $\begin{array}{l}\text { Direct and } \\
\text { embodied }\end{array}$ & $37 \%$ \\
\hline $\begin{array}{c}\text { Kratena and Wuger } \\
\qquad(2008)\end{array}$ & Austria & 6 & Efficiency & $\begin{array}{c}\text { Transport; heating; } \\
\text { electricity }\end{array}$ & Energy & Direct only & $37-86 \%$ \\
\hline
\end{tabular}


Brannlund et al (2007) was the first study to use cross-price elasticities to estimate combined direct and indirect rebound effects. Using survey data for Swedish households over the period 1980-1997, Brannlund et al estimate a household demand model $^{6}$ for 13 categories of nondurable expenditure. Separability assumptions are used to: first, allocate expenditure between durables and non-durables; second, allocate non-durable expenditure between four aggregate groups (food, transport, domestic energy and other); and third, distribute the group expenditures between individual commodities within each group (e.g. domestic energy is subdivided into oil, electricity and district heating). Brannlund et al then simulate a $20 \%$ energy efficiency improvement in transport and domestic energy by reducing the price of each commodity in proportion to the estimated contribution of energy to total costs, and then recalculate the model to estimate the impact on global carbon emissions. The results suggest a rebound effect of $121 \%$ for transport efficiency improvements, $175 \%$ for domestic energy and $140 \%$ for both combined. ${ }^{7}$

Brannlund et al do not separately investigate efficiency improvements in electricity and heating fuels, do not distinguish between direct and embodied emissions and do not calculate the relative contribution of income and substitution effects to their results - despite estimating the relevant elasticities. More importantly, their estimated rebound effects are remarkably large and suggest that direct rebound effects alone exceed $100 \%$. This contradicts the results of a growing body of work that estimates direct rebound effects for these energy services in OECD households (Sorrell et al., 2009), together with a larger body of work that estimates the corresponding energy price elasticities (Sorrell and Dimitropoulos, 2007b).

\footnotetext{
${ }^{6}$ All three of the studies described here estimate the linear Linear Almost Ideal Demand System (LAIDS) introduced by Deaton and Muellbauer (1980).

${ }^{7}$ The presentation of results is misleading. For example, transport efficiency is estimated to reduce carbon emissions by $6.2 \%$ in the absence of rebound effects but to increase carbon emissions by $1.3 \%$ once rebound effects are accounted for. Brannlund et al. report this as a rebound effect of $7.5 \%$, whereas the correct value is $121 \%$.
} 
Mizobuchi (2008) takes a similar approach to Brannlund et al, using monthly expenditure data for Japanese households over the period 1990-98. ${ }^{8}$ He also employs multistage budgeting, but in contrast to Brännlund et al, the 13 commodities represent expenditure on both durables and non-durables (e.g. both cars and road fuel) and hence cover all household emissions. Mizobuchi simulates simultaneous reductions in the price of domestic energy and road fuels, but the percentage improvements are different from those in Brannlund et al and vary from one commodity to another. Two scenarios are investigated: one where the efficiency improvements are costless, and a second where adjustments are made to reflect the additional capital cost of energy-efficient equipment. ${ }^{9}$ This leads to an estimated rebound effect of $115 \%$ in the first scenario (similar to Brannlund et al) and $27 \%$ in the second.

Mizobuchi argues that allowing for capital costs reduces the cost savings and hence the estimated rebound effects. But the manner in which this scenario is implemented also changes the relative cost savings between electricity, gas, heating oil and vehicle fuels, leading to substitution between them that modifies the estimated rebound effects. Since Mizobuchi does not report the rebound effects for each individual efficiency improvement, the drivers of the results are obscured.

Lin and Liu (2013) also follow Brannlund et al's approach, using annual data for Chinese urban households over the period 1986-2007. Their focus is a $30 \%$ improvement in energy efficiency for transport and domestic energy, but the assumed price reductions in each

\footnotetext{
${ }^{8}$ Methodological innovations include Bayesian estimation methods and the use of an iterative procedure to estimate rebound effects.

${ }^{9}$ Mizobuchi assumes $20 \%$ improvement in the efficiency of electricity and road fuel use, $10 \%$ in gas use and $3 \%$ in heating oil use. Achieving these is assumed to require a $22 \%$ increase in expenditure on durables for electricity, $35 \%$ for gas, $12 \%$ for heating oil and $28 \%$ for vehicles. The final percentage change in the price of the relevant subcategory (e.g. car transport) then depends upon the relative proportion of durable and nondurable expenditure within that category. The method of calculating additional capital costs is crude and leads, for example, to the odd result that fuel-efficient cars are more expensive than inefficient cars. This is because newer and more fuel-efficient cars of a particular model type are more expensive than older and less efficient cars of the same type. But this neglects the differences in cost and fuel efficiency between model types in the same year and between different sizes of vehicle.
} 
subcategory are not specified. They estimate a total rebound effect of $37 \%$, of which $12.6 \%$ is direct and $24.4 \%$ indirect. ${ }^{10}$ But they do not separately estimate the rebound effects for transport and domestic energy, and do not specify the relative contribution of income and substitution effects to their results.

Finally, Kratena and Wuger (2008) provide only a partial picture since they confine attention to a subset of commodity groups and neglect embodied emissions. They find large rebound effects (37-86\%), but this study has not been peer-reviewed and has a number of weaknesses (Sorrell, 2010).

In sum, the existing evidence base is limited and inadequately explained. The estimated rebound effects from both the Brannlund and Mizobuchi studies appear larger than those in Table 3 and inconsistent with the growing literature on direct rebound effects. Also, none of the studies in Table 4 clarify the relative contribution of income and substitution effects to their results, or the relative contribution of direct and embodied emissions. Our analysis addresses these limitations.

\section{Methodology}

Our approach involves estimating a household demand model to derive price and expenditure elasticities of different goods and services, utilising a multiregional input-output model to estimate the GHG emission intensities of those goods and services, combining the two to estimate direct and indirect rebound effects, and decomposing those effects to reveal the relative contribution of different mechanisms and commodities. Section 3.1 develops

\footnotetext{
${ }^{10}$ The numbers in the summary and abstract of Lin and Liu (2013) are incorrect, while those in the body of the paper are correct.
} 
analytical expressions for these effects, Section 3.2 describes the econometric model and Section 3.3 summarises the data.

\subsection{Rebound model}

Assume a household makes a costless investment that increases the energy efficiency $(\varepsilon)$ of providing an energy service $(s)$ by $\varsigma=\Delta \varepsilon / \varepsilon(\varsigma \geq 0)$, thereby reducing the energy cost $\left(p_{s}\right)$ of that service by $\tau=\Delta p_{s} / p_{s}(\tau \leq 0)$. Let $Q$ represent the household's baseline GHG emissions (direct plus embodied), $\Delta H$ the change in emissions that would occur without any behavioural responses to the lower cost energy service (the 'engineering effect'), $\Delta G$ the change in emissions that results from those behavioural responses (the 're-spending effect'), and $\Delta Q=\Delta H+\Delta G$ the net change in GHG emissions. The total rebound effect $\left(R_{T}\right)$ is then given by:

$$
R_{T}=\frac{\Delta H-\Delta Q}{\Delta H}=-\frac{\Delta G}{\Delta H}
$$

As discussed above, this is comprised of direct and indirect effects $\left(R_{T}=R_{D}+R_{I}\right)$ which may each be decomposed into income and substitution effects $\left(R_{D}=\hat{R}_{D}+\widetilde{R}_{D}\right.$ and $\left.R_{I}=\hat{R}_{I}+\widetilde{R}_{I}\right)$

The baseline GHG emissions for the household may be written as:

$$
Q=x_{s} u_{s}^{x}+\sum_{i(i \neq s)} u_{i}^{x} x_{i}
$$


Where $x_{i}$ is the expenditure on commodity $i$ (in $£$ ), $u_{i}^{x}$ is the GHG intensity of that expenditure (in $\mathrm{tCO}_{2 \mathrm{e}} / \mathfrak{f}$ ) and $x_{s}$ and $u_{s}^{x}$ are the corresponding values of these variables for the energy service. The GHG intensities include both direct and embodied emissions

To estimate the engineering effect $(\Delta H)$, we assume the consumption of all commodities remains unchanged while the energy cost of the energy service falls. The change in expenditure on the energy service as a consequence of the engineering effect is then given by $\Delta x_{s}^{H}=q_{s} \Delta p_{s}$. Given that $\Delta p_{s}=\tau p_{s}$ and $\Delta H=u_{s}^{x} \Delta x_{s}^{H}$ we obtain the following expression for the engineering effect:

$$
\Delta H=u_{s}^{x} x_{s} \tau
$$

To estimate the re-spending effect $(\Delta G)$, we must allow for the change in expenditure on each commodity group $\left(\Delta x_{i}\right)$. The change in expenditure on the energy service itself as a consequence of the engineering effect is given by $\Delta x_{s}^{G}=p_{s} \Delta q_{s} \cdot{ }^{11}$ Adding in the change of expenditure on other commodity groups we obtain the following expression for the respending effect:

$$
\Delta G=u_{s}^{x} \Delta x_{s}^{G}+\sum_{i(i \neq s)} u_{i}^{x} \Delta x_{i}
$$

Assuming marginal changes, we can use elasticities to substitute for $\Delta x_{s}^{G}$ and $\Delta x_{i}$ in this equation:

\footnotetext{
${ }^{11}$ For the energy service itself, the total change in expenditure is the sum of the engineering and re-spending effects: $\Delta x_{s}=\Delta x_{s}^{H}+\Delta x_{s}^{G}$
} 


$$
\Delta G=u_{s}^{x} x_{s} \tau\left(\eta_{x_{s}, p_{s}}-1\right)+\sum_{i(i \neq s)} u_{i}^{x} x_{i} \tau \eta_{x_{i}, p_{s}}
$$

Substituting the expressions for $\Delta H$ (Equation 14) and $\Delta G$ (Equation 16) into Equation 12 and noting that $w_{i}=x_{i} / x$, we arrive at the following expression for the total rebound effect:

$$
R_{T}=\left(1-\eta_{x_{s}, p_{s}}\right)-\sum_{i(i \neq s)} \psi_{i} \eta_{x_{i}, p_{s}}
$$

Where:

$$
\psi_{i}=\frac{u_{i}^{x} w_{i}}{u_{s}^{x} w_{s}}
$$

Using Equations 9 to 11, the total rebound effect can also be expressed as:

$$
R_{T}=-\eta_{q_{s}, p_{s}}-\sum_{i(i \neq s)} \psi_{i} \eta_{q_{i}, p_{s}}
$$

The first term in Equation 19 is the direct rebound effect $\left(R_{D}\right)$ and the second is the indirect effect $\left(R_{I}\right)$. The first depends solely upon the own-price elasticity of energy service demand $\left(\eta_{q_{s}, p_{s}}\right)$, while the second depends upon the elasticity of demand for commodity $i$ with respect to the energy service $\left(\eta_{q_{i}, p_{s}}\right)$ and the GHG intensity and expenditure share of that commodity relative to that of the energy service $\left(\psi_{i}\right)$. Hence, commodities with a small cross price elasticity may nevertheless contribute a large indirect rebound effect if they are relatively GHG intensive and/or have a large expenditure share (and vice versa).

Using the Slutsky equation, we decompose Equation 19 as follows: 


$$
R_{T}=\left[w_{s} \eta_{q_{s}, x}-\tilde{\eta}_{q_{s}, p_{s}}\right]+\left[\sum_{i(i \neq s)}\left[\psi_{i} w_{s} \eta_{q_{i}, x}-\psi_{i} \tilde{\eta}_{q_{i}, p_{s}}\right]\right]
$$

As noted, the challenges of incorporating energy services within a household demand model make it difficult to implement this approach directly. Hence, in what follows we estimate the required elasticities with respect to energy commodities $(l)$ rather than energy services $(s)$. Table 5 summarises the required expressions.

Table 5 Analytical expressions for the components of the rebound effect

\section{Direct rebound effect}

Indirect rebound effect for commodity $i$

\begin{tabular}{lll}
\hline Income effect & $\hat{R}_{D}=w_{l} \eta_{x_{l}, x}$ & $\hat{R}_{I}=\psi_{i} w_{l} \eta_{x_{i}, x}$ \\
\hline Substitution effect & $\widetilde{R}_{D}=1-\tilde{\eta}_{x_{l}, p_{l}}$ & $\tilde{R}_{I}=-\psi_{i} \tilde{\eta}_{x_{i}, p_{l}}$ \\
& \\
\hline
\end{tabular}

\subsection{Econometric model}

As with the other studies in Table 4, we base our household demand model on the Linear Approximation to the Almost Ideal Demand System (LAIDS). This has become the model of choice in household demand analysis since it has number of advantages over competing approaches (Deaton and Muellbauer, 1980). As a compromise between resolution and degrees of freedom, we split household expenditure into 12 subcategories (Table 6) and assume separability to give a two-stage budgeting framework (Figure 1). Households are assumed to first allocate expenditure between four aggregate groups $(r)$, and then distribute the group expenditures between individual commodities within each group $(i)$. This framework allows expenditure on commodities within a group to be specified as a function of 
group expenditure and the prices of commodities within the group alone. As with Mizobuchi (2008), the commodity categories include both durables and nondurables.

Table 6 Categories of goods and services

\begin{tabular}{|c|c|c|c|}
\hline $\begin{array}{c}\text { Aggregate Group }(r) \\
\text { Stage } 1\end{array}$ & $\begin{array}{l}\text { Category }(i) \\
\text { Stage } 2\end{array}$ & $\begin{array}{l}\text { COICOP } \\
\text { category }\end{array}$ & Description \\
\hline \multirow{2}{*}{$\begin{array}{l}\text { 1. Food and } \\
\text { beverages }\end{array}$} & 1 & 1 & Food and non-alcoholic beverages \\
\hline & 2 & 2 & Alcoholic beverages, tobacco, narcotics \\
\hline \multirow[t]{2}{*}{ 2. Transport } & 3 & 7.2.2.2 & Vehicle fuels and lubricants \\
\hline & 4 & Rest of 7 & Other transport \\
\hline \multirow[t]{3}{*}{ 3. Energy } & 5 & 4.5 .1 & Electricity \\
\hline & 6 & 4.5 .2 & Gas \\
\hline & 7 & 4.5 .3 and 4.5 .4 & Other fuels \\
\hline \multirow{11}{*}{$\begin{array}{l}\text { 4. Other goods and } \\
\text { services }\end{array}$} & 8 & 9 & \\
\hline & & & Recreation \& culture \\
\hline & 9 & 11 & Restaurants \& hotels \\
\hline & 10 & 10 & Education \\
\hline & 11 & 8 & Communication \\
\hline & 12 & & Other \\
\hline & & 3 & Clothing and footwear \\
\hline & & 4.1 to 4.4 & Other housing \\
\hline & & 5 & $\begin{array}{l}\text { Furnishings, household equipment \& } \\
\text { household maintenance }\end{array}$ \\
\hline & & 6 & Health \\
\hline & & 12 & Miscellaneous goods and services \\
\hline
\end{tabular}

Notes: COICOP - Classification of Individual Consumption According to Purpose. 'Other housing' includes rent, mortgage payments, maintenance, repair and water supply. 'Other transport' includes public transport, nonfuel expenditure on private vehicles and some aviation - although air travel for package holidays is included within 'recreation and culture'. 'Other fuels' include solids and liquids. 
Figure 1 Two-stage budgeting model

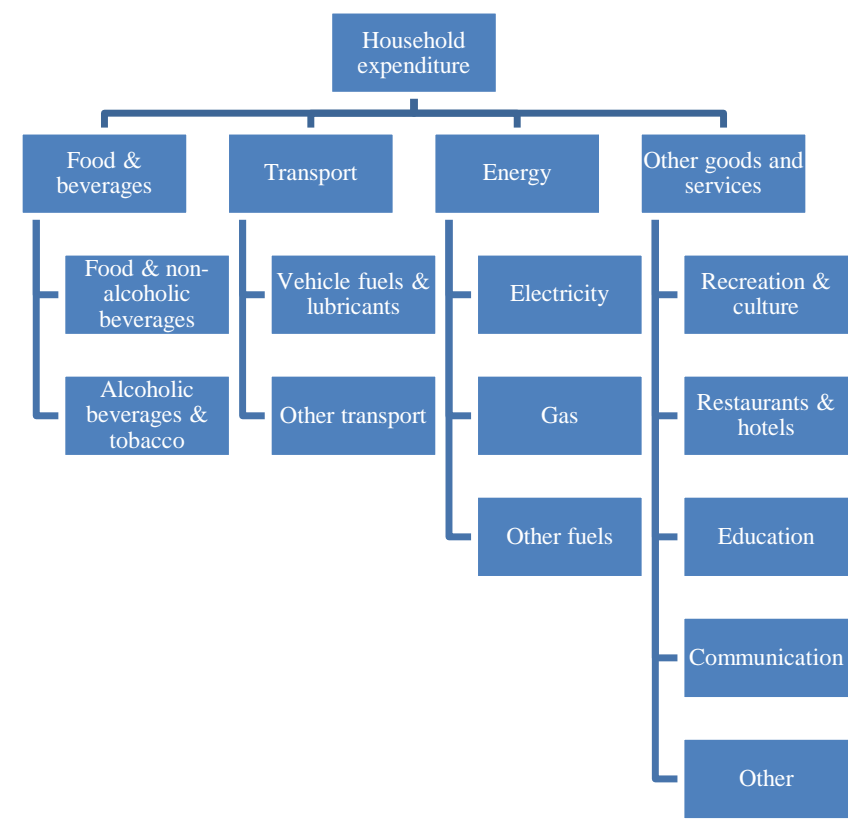

Let $x_{t}^{r}$ represent the expenditure on aggregate commodity group $r$ in period $t$ and $w_{t}^{r}$ the fractional share of that group in total household expenditure $\left(x_{t}\right)$ :

$$
w_{t}^{r}=\frac{x_{t}^{r}}{x_{t}}
$$

In the first stage of the AIDS model, this is specified as:

$$
w_{t}^{r}=\alpha^{r}+\sum_{s=1, . .4} \gamma^{r s} \ln p_{t}^{s}+\beta^{r} \ln \left(x_{t} / P_{t}\right)+\sum_{s=1, . .3} \lambda^{r s} w_{t-1}^{s}+\varepsilon_{t}^{r}
$$

Where: $r$ and $s$ index over the aggregate commodity groups; $p_{t}^{s}$ is the price of the aggregate commodity group $s$ in period $t ; x_{t}$ is total expenditure per household in that period; $P_{t}$ is the Stone's price index for the aggregate commodities; $w_{t-1}^{s}$ is the lagged expenditure share of commodity group $s ; \alpha^{r}, \gamma^{r s}, \beta^{r}$ and $\lambda^{r s}$ are the unknown parameters and $\varepsilon_{t}^{r}$ is the error term. The Stone's price index is defined as: 


$$
\ln P_{t}=\sum_{r=1, . .4} w_{t}^{r} \ln p_{t}^{r}
$$

Given the constraints on degrees of freedom, we do not include additional covariates. However, our model departs from standard applications of LAIDS by including lagged expenditure shares $\left(w_{t-1}^{s}\right)$ to capture the inertia in price responses - for example as a result of habit formation. The inclusion of lags also reduces problems of serial correlation (Edgerton, 1997; Klonaris and Hallam, 2003; Ray, 1983; Ryan and Plourde, 2009; Shukur, 2002). Since the lagged expenditure shares sum to unity, we only include three in each equation to avoid multi-collinearity. ${ }^{12}$

Restrictions are often imposed upon the parameter values to ensure the results are compatible with consumer demand theory. Specifically, adding up requires that expenditures on each commodity add up to total expenditure; homogeneity requires that quantity demanded remains unchanged if prices and total expenditure change by an equal proportion; and symmetry requires that the compensated cross-price elasticities between two commodities are equal. These may be implemented as follows:

Adding up: $\quad \sum_{r} \alpha^{r}=1 ; \sum_{r} \beta^{r}=0 ; \sum_{r} \gamma^{r s}=0 s=1, . .4 ; \quad$ and $\sum_{r} \lambda^{r s}=0 \quad s=1, . .3$;

Homogeneity: $\sum_{r} \gamma^{r s}=0 s=1, . .4$;

Symmetry: $\quad \gamma^{r s}=\gamma^{s r}$

\footnotetext{
${ }^{12}$ An alternative to dropping the lagged budget share of one commodity would be to impose the restriction: $\sum_{s} \lambda^{r s}=0$. This would not affect the estimated coefficients.
} 
The second stage of the AIDS model distributes the group expenditures $\left(x_{t}^{r}\right)$ between individual commodities within each group. Let $x_{i t}^{r}$ represent expenditure on commodity $i$ in aggregate group $r$ during period $t(i \in r)$ and $w_{i t}^{r}$ represent the fractional share of that commodity in the expenditure on group $r\left(x_{t}^{r}\right)$ :

$$
w_{i t}^{r}=\frac{x_{i t}^{r}}{x_{t}^{r}}
$$

This is specified as:

$$
w_{i t}^{r}=\alpha_{i}^{r}+\sum_{j=1, . . k^{r}} \gamma_{i j}^{r} \ln p_{i j}^{r}+\beta_{i}^{r} \ln \left(x_{t}^{r} / P_{t}^{r}\right)+\sum_{j=1, . .\left(k^{r}-1\right)} \lambda_{i j}^{r} w_{j t-1}^{r}+\varepsilon_{i t}^{r}
$$

Where: $i$ and $j$ index over the commodities within aggregate group $r(i, j \in r) ; k^{r}$ is the number of commodities in aggregate group $r ; p_{i t}^{r}$ is the price of commodity $i$ in period $t ; x_{t}^{r}$ is expenditure on group $r$ in that period; $P_{t}^{r}$ is the Stone's price index for group $r ; \alpha_{i}^{r}, \gamma_{i j}^{r}$ $\beta_{i}^{r}$ and $\lambda_{i j}^{r}$ are the unknown parameters and $\varepsilon_{i t}^{r}$ is the error term. The Stone's price index for group $r$ is defined as:

$$
\ln P_{t}^{r}=\sum_{i=1, . . k^{r}} w_{i t}^{r} \ln p_{i t}^{r}
$$

Again, the adding up, symmetry and homogeneity restrictions can be imposed as follows:

Adding up: $\quad \sum_{i} \alpha_{i}^{r}=1 ; \sum_{i} \beta_{i}^{r}=0 ; \sum_{i} \gamma^{i j}=0 ; j=1, . . k^{r}$ and $\sum_{i} \lambda_{i j}^{r}=0 j=1, .\left(k^{r}-1\right)$ 
Homogeneity: $\sum_{i} \gamma_{i j}^{r}=0 j=1, . . k^{r}$

Symmetry: $\quad \gamma_{i j}^{r}=\gamma_{j i}^{r}$

Alternatively, an unrestricted model can be estimated for both first and second stage and the homogeneity and symmetry restrictions tested. It is common for these restrictions to be rejected in empirical studies (Keuzenkamp and Barten, 1995). ${ }^{13}$ The adding up restriction, however, is always satisfied by dropping one of the equations.

Godard (1983) derives equations for estimating the short run expenditure and price elasticities for a single stage LAIDS model ${ }^{14}$, while Edgerton (1997) derives expressions for a two-stage model. In the latter, 'total' elasticities are calculated from estimates of the 'between-group' and 'within-group' elasticities. The interpretation of these is summarised in Box 1 while the relevant formulae are summarised in Table 7 (Edgerton, 1997). Here, $\delta_{r s}$ (Kronecker delta) is equal to unity when $r=s$ (i.e. own-price elasticity) and zero otherwise. Similarly, $\delta_{i j}^{r}$ is unity when $i=j$ and zero otherwise.

\footnotetext{
${ }^{13}$ For example, the foundational AIDS study by Deaton and Muellbauer (1980) rejected these restrictions.

${ }^{14}$ Buse (1994) evaluates several elasticity expressions for LAIDS model and finds these expressions are marginally the best.
} 
Box 1 Interpretation of the between-group, within-group and total elasticities

1. Between-group expenditure $\left(\eta_{x_{r}, x}\right)$ and price $\left(\eta_{x_{r}, p_{s}}\right.$ and $\left.\tilde{\eta}_{x_{r}, p_{s}}\right)$ elasticities for the aggregate commodity groups $(r)$ respectively indicate how expenditure on aggregate group $r$ changes following: a) a change in total expenditure; and b) a change in the price of aggregate group $s$ holding total expenditure fixed.

2. Within-group expenditure $\left(\eta_{x_{i}, x_{r}}^{r}\right)$ and price $\left(\eta_{x_{i}, p_{j}}^{r}\right.$ and $\left.\tilde{\eta}_{x_{i}, p_{j}}^{r}\right)$ elasticities for each commodity $i$ within aggregate group $r$ respectively indicate how expenditure on this commodity changes following: a) a change in expenditure on group $r$; and b) a change in the price of commodity $j$ within aggregate group $r$ holding expenditure on group $r$ fixed. Here, both $i$ and $j$ are within the same aggregate group.

3. Total expenditure $\left(\eta_{x_{i}, x}\right)$ and price $\left(\eta_{x_{i}, p_{j}}\right.$ and $\left.\tilde{\eta}_{x_{i}, p_{j}}\right)$ elasticities for each commodity $i$ within aggregate group $r$ respectively indicate how expenditure on this commodity changes following: a) a change in total expenditure; and b) a change in the price of commodity $j$ holding total expenditure fixed but allowing expenditure on group $r$ to vary. Here, $i$ and $j$ may be within the same or different aggregate group. 
Table 7: Analytical expressions for the between-group, within-group and total elasticities within a two-stage LAIDS model

\begin{tabular}{|c|c|c|c|}
\hline Elasticity & Between-group & Within-group $(i, j \in r)$ & Total \\
\hline Expenditure & $\eta_{x_{r}, x}=1+\frac{\beta^{r}}{w^{r}}$ & $\eta_{x_{i}, x_{r}}^{r}=1+\frac{\beta_{i}^{r}}{w_{i}^{r}}$ & $\eta_{x_{i}, x}=\eta_{x_{i}, x_{r}}^{r} \eta_{x_{r}, x}$ \\
\hline Uncompensated price & $\eta_{x_{r}, p_{s}}=\frac{\gamma^{r s}-\beta^{r} w_{s}}{w_{r}}-\delta_{r s}$ & $\eta_{x_{i}, p_{j}}^{r}=\frac{\gamma_{i j}^{r}-\beta_{i}^{r} w_{j}^{r}}{w_{i}^{r}}-\delta_{i j}^{r}$ & $\eta_{x_{i}, p_{j}}=\delta_{r s} \eta_{x_{i}, p_{j}}^{r}+\eta_{x_{i}, x_{r}}^{r}\left(\delta_{r s}+\eta_{x_{r}, p_{s}}\right) w_{j}^{s}$ \\
\hline Compensated price & $\tilde{\eta}_{x_{r}, p_{s}}=\frac{\gamma^{r s}}{w_{r}}+w_{s}-\delta_{r s}$ & $\tilde{\eta}_{x_{i}, p_{j}}^{r}=\frac{\gamma_{i j}^{r}}{w_{i}^{r}}+w_{j}^{r}-\delta_{i j}^{r}$ & $\tilde{\eta}_{x_{i}, p_{j}}=\delta_{r s} \tilde{\eta}_{x_{i}, p_{j}}^{r}+\eta_{x_{i}, x_{r}}^{r}\left(\delta_{r s}+\tilde{\eta}_{x_{r}, p_{s}}\right) w_{j}^{s}$ \\
\hline
\end{tabular}

Source: Edgerton (1997); Goddard (1983) 
The formulae in Table 7 deserve some explanation. The formula for the total expenditure elasticity for the $i$ th commodity in the $r$ th group (Table 7, line 2 ) is simply the product of the within-group elasticity for that commodity and the expenditure elasticity of the group.

The formula for the total uncompensated price elasticity (Table 7, line 3) is more complex. Note first that when commodities $i$ and $j$ are in different groups, $\delta_{r s}=0$ and the expression reduces to:

$$
\eta_{x_{i}, p_{j}}=\eta_{x_{i}, x_{r}}^{r} \eta_{x_{r}, p_{s}} w_{j}^{s}
$$

Here, the first term $\left(\eta_{x_{i}, x_{r}}^{r}\right)$ represents the change in expenditure on commodity $i$ following a change in expenditure on group $r$; the second term represents the change in expenditure on group $r$ following a change in the price of group $s$; and the third term represents the share of commodity $j$ in the expenditure on group $s$. As shown by Edgerton (1997), the latter is equivalent to the change in the price of group $s$ following a change in the price of commodity $j\left(w_{j}^{s}=\partial \ln p_{s} / \partial \ln p_{j}\right)$.

When $i$ and $j$ are in the same group $(r=s)$, the expression becomes:

$$
\eta_{x_{i}, p_{j}}=\eta_{x_{i}, p_{j}}^{r}+\eta_{x_{i}, x_{r}}^{r}\left(1+\eta_{x_{r}, p_{r}}\right) w_{j}^{r}
$$

Here, the total cross price elasticity equals the within-group cross price elasticity $\left(\eta_{x_{i}, p_{j}}^{r}\right)$, plus a product of three factors. The first of these $\left(\eta_{x_{i}, x_{r}}^{r}\right)$ measures the change in expenditure on commodity $i$ following a change in expenditure on group $r$; the second measures the change in expenditure on group $r$ following a change in the price of group $r$; and the third represents the change in the price of group $r$ following a change in the price of commodity $j$ 
$\left(w_{j}^{r}=\partial \ln p_{r} / \partial \ln p_{j}\right)$.The smaller each of these terms are, the smaller the difference between the within-group and total price elasticity. The formula for the total compensated price elasticity (Table 7, line 4) follows a similar pattern.

Following standard practice, we estimate the elasticities using the mean values of the expenditure shares over the full time series. The total elasticities are used for estimating rebound effects.

\subsection{Data}

Data for the price of different commodity groups and household expenditure on those groups is taken from Consumer Trends, published by the UK Office of National Statistics (ONS). The period chosen is 1964 to 2013 and the values are converted to current prices using a base year of 2010. Data on total household numbers for selected years is taken from DGLC (2014), with data on intermediate years estimated by linear interpolation. ${ }^{15}$ Figure 2 indicates the change in expenditure shares over this period both between and within-groups. During this period, the share of food in total expenditure almost halved, the share of transport increased by $50 \%$ and the share of energy fell by $30 \%$. Within the energy group, substitution by gas reduced the expenditure share of other fuels (coal and oil) from $42 \%$ in 1964 to $6 \%$ in $2013 .^{16}$

\footnotetext{
15 Two sets of time series data for expenditure and implied deflators are available: a) 1964 to 2010 consistent with the UK National Accounts for 2010 (ONS, 2010) and b) 1997 to 2013 consistent with the National Accounts for 2011 (ONS, 2011). To create a consistent time series over the full period, we take the annual growth rates of expenditure and deflators during 1964-1997 from ONS (2010) and use these to adjust the 1997 data from ONS (2011).

${ }^{16}$ Since our analysis uses mean values of expenditure shares, the estimated contribution of other fuels is larger, and the estimated contribution of transport is lower, than would be the case if we had used 2013 values of expenditure shares.
} 
Figure 2 Trends in UK household expenditure shares between 1964 and 2013

\section{Total expenditure}

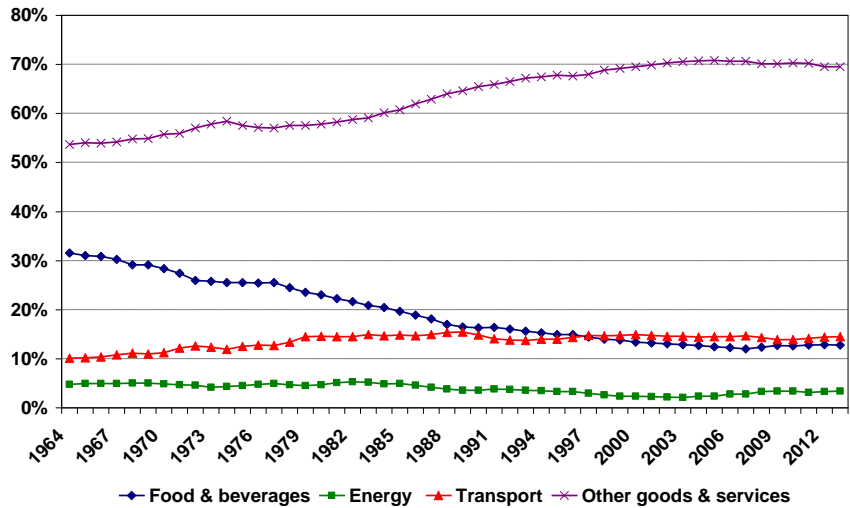

Food and non-alcoholic beverages

Energy

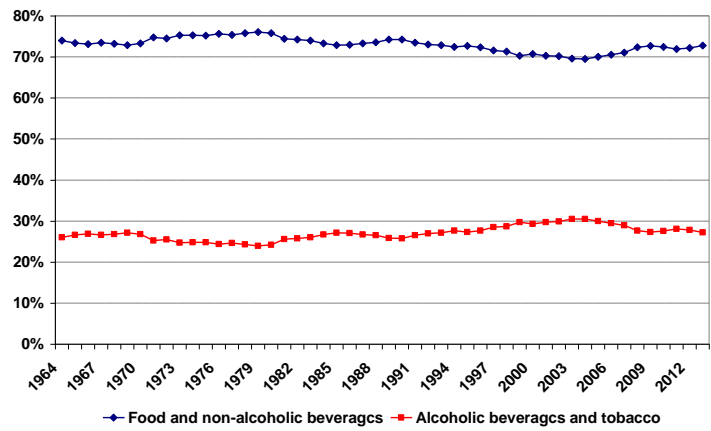

Transport

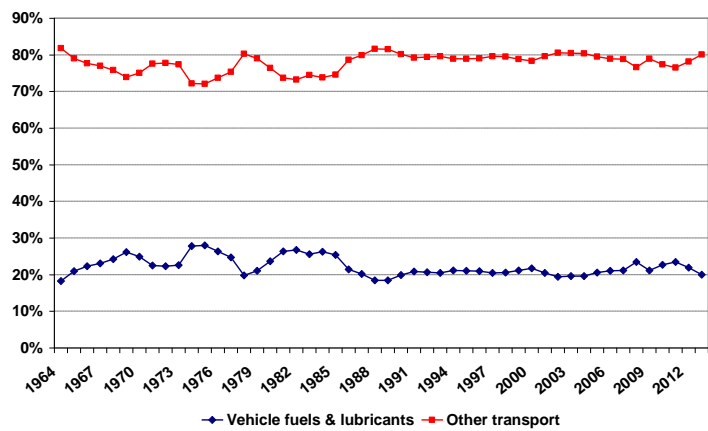

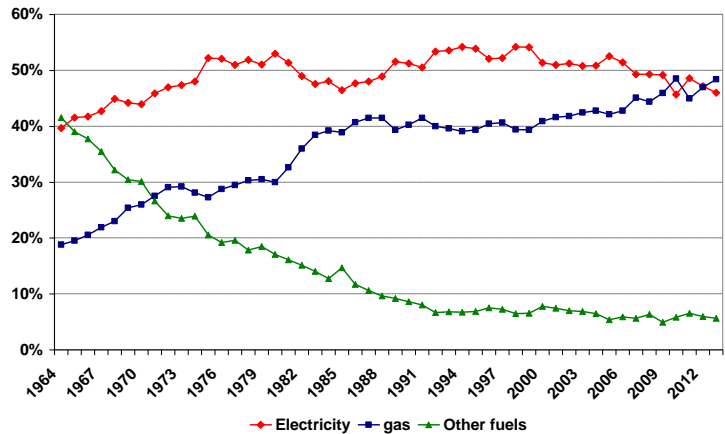

Other goods and services

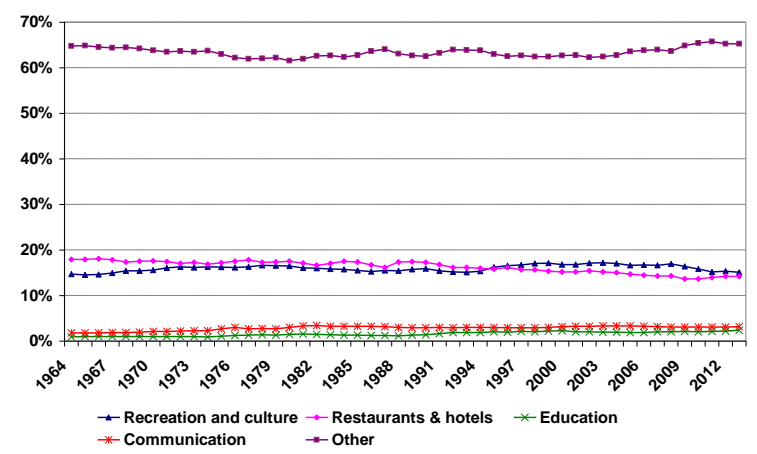


Our data source for the GHG emissions associated with different categories of goods and services is the Surrey Environmental Lifestyle Mapping Framework (SELMA). This is a quasi-multi-regional, environmentally extended input-output model that provides estimates of the GHG intensity of UK household expenditure in each category (in $\mathrm{tCO}_{2} \mathrm{e} / \mathfrak{E}$ ) for 2004 (Druckman and Jackson, 2008). ${ }^{17}$ These figures include both the direct emissions from the consumption of electricity ${ }^{18}$, heating fuels and vehicle fuels, and the embodied emissions from each stage of the supply chain for goods and services - which may occur either in the UK or overseas. We adjust these estimates to allow for the emissions associated with government expenditure of product taxation revenues. ${ }^{19}$

Figure 3 (top) shows that expenditure on electricity, gas and other fuels is approximately twice as GHG intensive as expenditure on vehicle fuels and approximately four times as GHGs intensive as expenditure on other transport - which is the next most GHG intensive category. Overall, expenditure on energy commodities is approximately five times as GHG intensive as the share-weighted mean. But the high GHG intensity of energy commodities is offset by their small share of total expenditure (7\% - Figure 3, middle), with the result that direct energy consumption only accounts for $27 \%$ of an average household's 'GHG footprint'

\footnotetext{
${ }^{17}$ The GHG intensity of a category is estimated from the GHG emissions associated with that category in 2004 (obtained from SELMA) divided by 'real' expenditure on that category in 2004 (reference year 2013). The exception is electricity where emissions are estimated from 2012 electricity consumption (in $\mathrm{kWh}$ ) multiplied by an emission factor for 2012 $\left(\mathrm{kgCO}_{2} \mathrm{e} / \mathrm{kWh}\right)$. This adjustment is designed to reflect the large reduction in the GHG intensity of electricity

${ }^{18}$ Emissions from electricity consumption are commonly labelled as direct, although they occur at the power station.

${ }^{19}$ Environmentally-Extended Input-Output (IO) models such as SELMA only include the GHG emissions associated with each expenditure category. But expenditures on different commodities include various taxes (such as Value Added Tax - VAT) which in turn are used to fund government expenditure. Since government spending is a separate category in the national accounts, the associated GHG emissions are normally excluded from the estimated GHG intensities of household expenditure. Exclusion of these emissions could bias estimates of rebound effects, in particular because differing levels of product taxation are applied to different goods and services. For example, in the UK there is $20 \%$ VAT on most goods and services; 5\% VAT on electricity, gas and other fuels; zero rate VAT on most food products; and around $65 \%$ taxation on vehicle fuels. To eliminate this potential bias we: first, estimate the GHG intensity of UK government expenditure in 2004; second, use this to estimate the GHG emissions associated with taxation in each category; and third, add these to the emissions provided by SELMA for each expenditure category. This in turn leads to an adjusted GHG intensity of expenditure for each category which is used in the calculation of rebound effects. As the GHG intensity of government expenditure is relatively low, this adjustment does not significantly change our results.
} 
(Figure 3, bottom), split between 19\% domestic energy (i.e. electricity, gas and other fuels) and $8 \%$ vehicle fuels.

The category providing the largest single contribution (25\%) to total emissions is 'other goods and services' which includes expenditure on clothing, housing maintenance, water and furnishings and accounts for $45 \%$ of expenditure. The next highest is 'other transport' $(12 \%)$ which includes non-fuel costs for private cars, public transport and some air travel. Since these categories have both a relatively high expenditure share and a relatively high GHG intensity they provide a significant contribution to total emissions (42\%).

Our estimates of GHG intensities allow for the variation of product taxation between categories: namely VAT exemption for food and non-alcoholic beverages, lower rate VAT for domestic energy and high taxation of vehicle fuels ( $60 \%$ of retail price). The latter contributes to the comparatively low GHG intensity of vehicle fuels compared to domestic energy. 
Figure 3 GHG intensity of expenditure, share of total expenditure and share of total GHG emissions by category for an average household
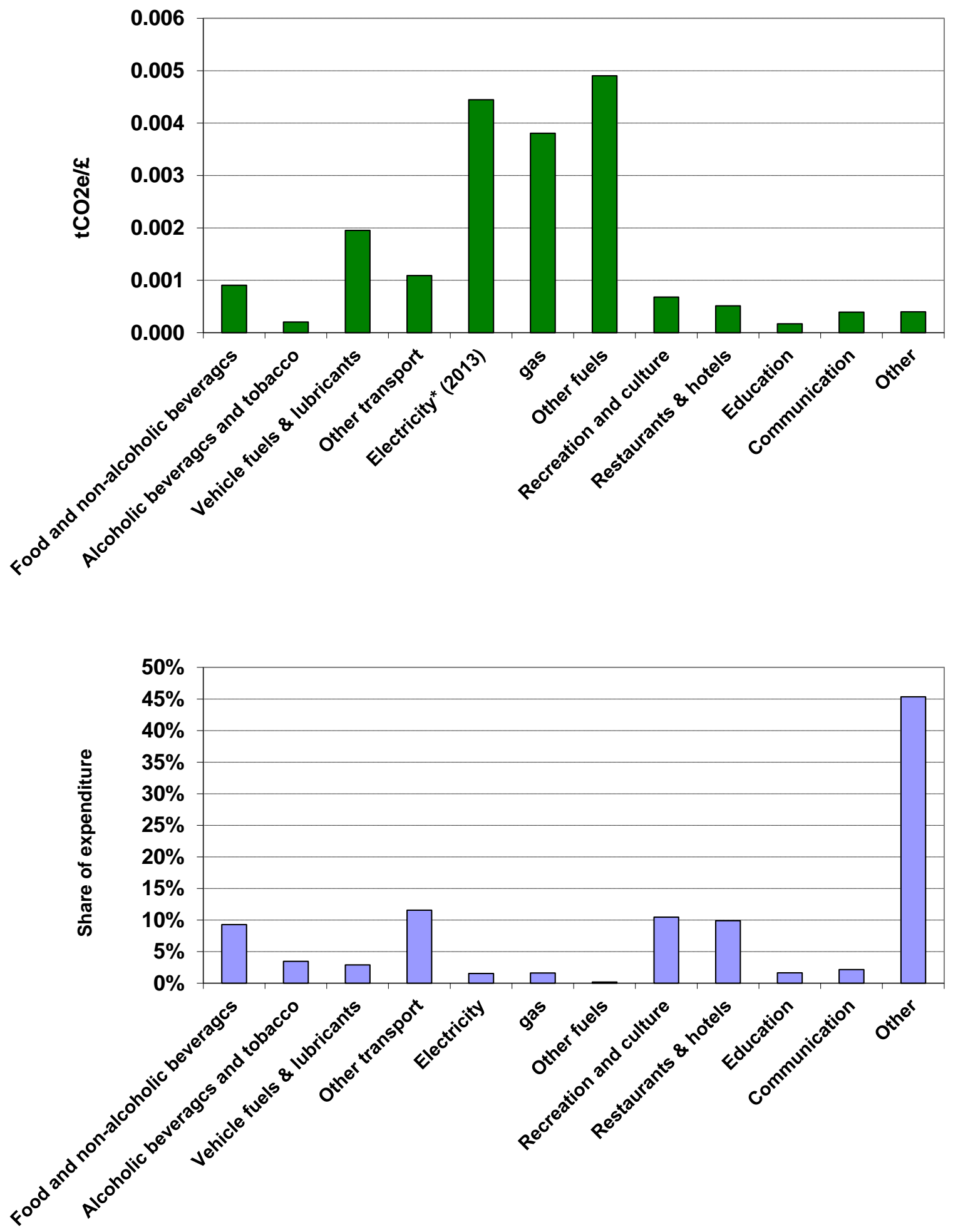


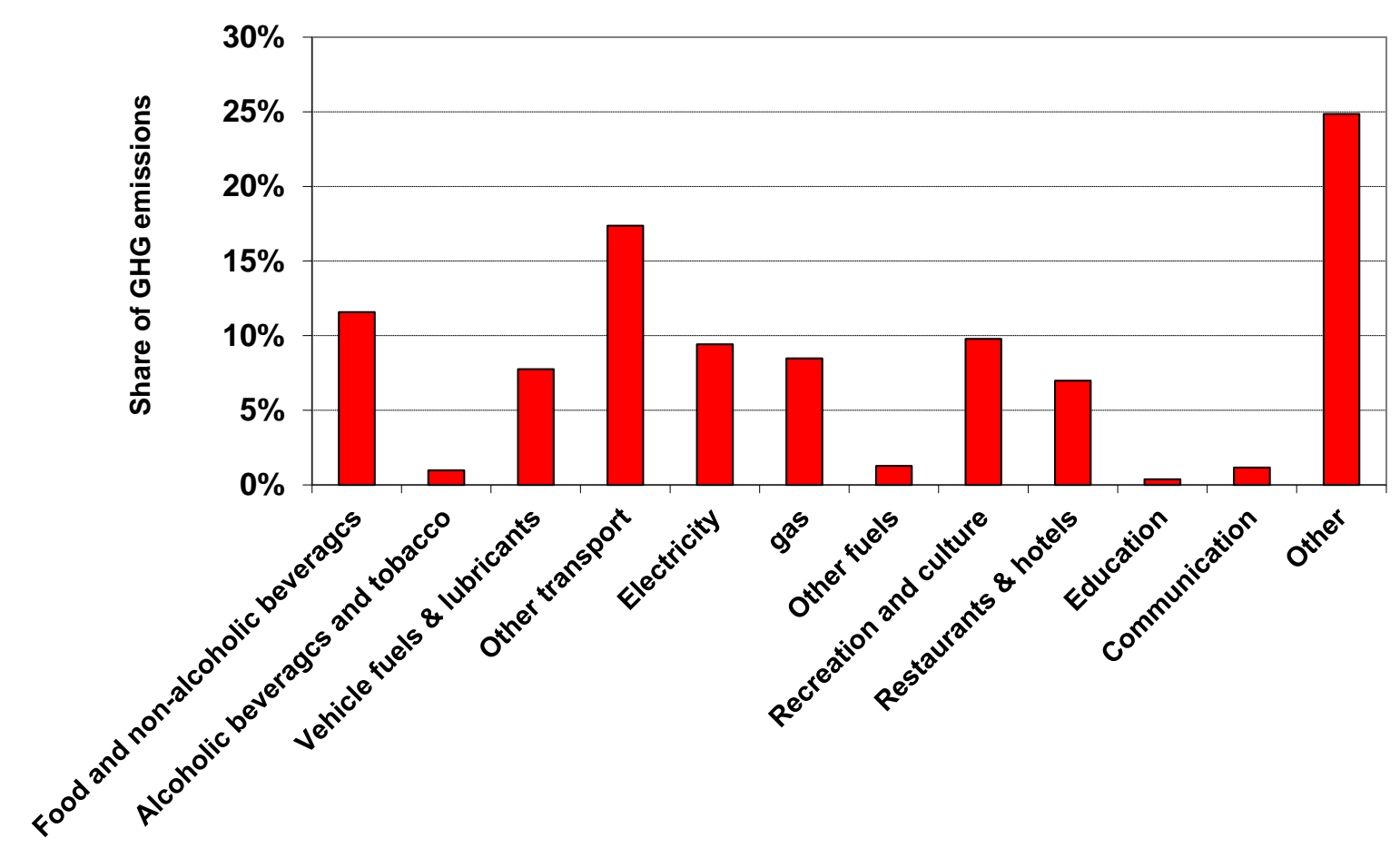

\section{Results}

\subsection{Econometric results}

The two-stage budgeting assumptions model in Figure 1 leads to a total of 16 equations in five groups. The equations in each group are estimated as a system using the Iterative Seemingly Unrelated Regressions (ISUR) method which is suitable for imposing crossequation restrictions and corrects the estimates for any correlation of the error terms between equations. The adding up restriction is imposed by dropping one of the equations in each group.

The equations in each group are first estimated without imposing homogeneity and symmetry restrictions. A Wald test is then used to test for these restrictions both individually and in combination. If homogeneity and/or symmetry are not rejected then they are imposed on the relevant group. 
Annex 1 summarises the parameter estimates for each group of equations and the results of the restrictions. Annex 2 summarises the between-group elasticity estimates, and Annex 3 summarises the within-group estimates. The most relevant results are the total elasticity estimates for the energy and transport groups which are summarised in Tables 8 to 10. For ease of interpretation, all elasticities are expressed for quantities $(q)$ rather than expenditure shares $(w)$.

Looking first at Annex 1 (Tables A.1 to A.5), we see that the overall fit of the equations is good, with more than two thirds of the parameter estimates being statistically significant at the $5 \%$ level and with most of the equations having an adjusted $R^{2}$ exceeding $90 \%$. From Table A.6 we see that both homogeneity and symmetry restrictions are rejected for the energy group, hence we use the non-restricted results for this group. For all other groups only the homogeneity restriction cannot be rejected. Hence, we impose homogeneity in all non-energy groups, but we do not impose symmetry on any group. We also use the Portmanteau serial correlation test for each group and find no evidence of serial correlation.

Looking at the total elasticity estimates (Tables 8-10), we make several observations. First, the expenditure elasticities for domestic energy are relatively low -0.07 for electricity and 0.15 for gas. These values are broadly comparable with those estimated from cross-sectional data in our previous work (Chitnis et al., 2014) where we showed that high-income groups have very low expenditure elasticities for these commodities - which in turn has a disproportionate influence on the overall mean. In contrast, the estimated expenditure elasticities for vehicle fuels, 'other transport' and the sub-categories of 'other goods and services' all exceed unity, indicating that they are luxury goods. 
Second, the own-price elasticities for energy commodities have the expected sign with values of -0.39 for electricity, -0.59 for gas and -0.59 for vehicle fuels. For comparison, a review of studies by Espey and Espey (2004) found a mean short-run elasticity of -0.35 (median -0.28) for electricity; a study by Asche et al. (2008)found short run elasticities of household natural gas demand to be -0.25 or less; and a review of studies by Goodwin et al. (2004) found a mean short-run elasticity for vehicle fuels of -0.25 . Hence, our estimates appear to be at the high end of the range found in the literature - especially for gas and vehicle fuels. Since the expenditure elasticities for these commodities are relatively small, the own-price response is primarily driven by substitution effects - as is indicated by the near equivalence of the compensated and uncompensated elasticities for these commodities (Tables 9 and 10).

Third, electricity and gas are found to be substitutes, and both of these are estimated to be substitutes for vehicle fuels when the price of the latter changes, but complements when their own-price changes (symmetry is not imposed). In addition, both 'other transport' and all subcategories within 'other goods and services' are estimated to be complements to energy commodities and will therefore contribute a negative indirect rebound effect. In contrast, food and drink products are estimated to be substitutes and will contribute a (small) positive indirect rebound effect.

Overall, the results suggest that the substitution effects for energy commodities outweigh the income effects, and changes in the price of one or more energy commodities will have their largest impact on the quantity of energy commodities demanded. Since energy commodities are also GHG intensive, they are likely to dominate the total rebound effect. This is demonstrated below, where we report the rebound results. 
Table 8 Total expenditure elasticities $\left(\eta_{q_{i} x}\right)$

\begin{tabular}{|c|c|c|c|c|c|c|c|c|c|c|c|c|}
\hline & \multicolumn{3}{|c|}{ Energy } & \multicolumn{2}{|c|}{ Transport } & \multicolumn{2}{|c|}{ Food and beverages } & \multicolumn{5}{|c|}{ Other goods and services } \\
\hline & Electricity & Gas & $\begin{array}{l}\text { Other } \\
\text { fuels }\end{array}$ & $\begin{array}{l}\text { Vehicle } \\
\text { fuels }\end{array}$ & $\begin{array}{c}\text { Other } \\
\text { transport }\end{array}$ & $\begin{array}{c}\text { Food \& } \\
\text { non- } \\
\text { alcoholic } \\
\text { beverages }\end{array}$ & $\begin{array}{c}\text { Alcoholic } \\
\text { beverages \& } \\
\text { tobacco }\end{array}$ & $\begin{array}{l}\text { Recreation } \\
\text { and culture }\end{array}$ & $\begin{array}{l}\text { Restaurants } \\
\text { and hotels }\end{array}$ & Education & Communication & Other \\
\hline $\begin{array}{l}\text { Expenditure } \\
\text { elasticity }\end{array}$ & 0.07 & 0.15 & 0.16 & 1.01 & 1.33 & 0.71 & 0.88 & 1.22 & 1.15 & 1.23 & 1.06 & 1.01 \\
\hline
\end{tabular}

Table 9 Total compensated cross price elasticities- energy group $\left(\tilde{\eta}_{q_{i} p_{j}}\right)$

\begin{tabular}{|c|c|c|c|c|c|c|c|c|c|c|c|c|}
\hline & \multicolumn{3}{|c|}{ Energy } & \multicolumn{2}{|c|}{ Transport } & \multicolumn{2}{|c|}{ Food and beverages } & \multicolumn{5}{|c|}{ Other goods and services } \\
\hline & Electricity & Gas & $\begin{array}{l}\text { Other } \\
\text { fuels }\end{array}$ & $\begin{array}{l}\text { Vehicle } \\
\text { fuels }\end{array}$ & $\begin{array}{c}\text { Other } \\
\text { transport }\end{array}$ & $\begin{array}{l}\text { Food and } \\
\text { non- } \\
\text { alcoholic } \\
\text { beverages }\end{array}$ & $\begin{array}{c}\text { Alcoholic } \\
\text { beverages \& } \\
\text { tobacco }\end{array}$ & $\begin{array}{l}\text { Recreation } \\
\text { and culture }\end{array}$ & $\begin{array}{l}\text { Restaurants } \\
\text { and hotels }\end{array}$ & Education & Communication & Other \\
\hline Electricity & -0.39 & 0.11 & -0.08 & -0.04 & -0.06 & 0.04 & 0.05 & 0.01 & 0.01 & 0.01 & 0.01 & 0.01 \\
\hline Gas & 0.07 & -0.58 & 0.37 & -0.03 & -0.04 & 0.03 & 0.03 & 0.01 & 0.01 & 0.01 & 0.01 & 0.01 \\
\hline $\begin{array}{l}\text { Other } \\
\text { fuels }\end{array}$ & 0.04 & 0.12 & -0.76 & -0.01 & -0.02 & 0.01 & 0.01 & 0.003 & 0.003 & 0.003 & 0.003 & 0.003 \\
\hline $\begin{array}{l}\text { Vehicle } \\
\text { fuels }\end{array}$ & 0.07 & 0.15 & 0.16 & -0.55 & 0.04 & 0.01 & 0.01 & 0.01 & 0.01 & 0.01 & 0.01 & 0.01 \\
\hline
\end{tabular}


Table 10 Total uncompensated cross price elasticities-energy group $\left(\eta_{q_{i} p_{j}}\right)$

\begin{tabular}{|c|c|c|c|c|c|c|c|c|c|c|c|c|}
\hline & \multicolumn{3}{|c|}{ Energy } & \multicolumn{2}{|c|}{ Transport } & \multicolumn{2}{|c|}{ Food and beverages } & \multicolumn{5}{|c|}{ Other goods and services } \\
\hline & Electricity & Gas & $\begin{array}{l}\text { Other } \\
\text { fuels }\end{array}$ & $\begin{array}{l}\text { Vehicle } \\
\text { fuels }\end{array}$ & $\begin{array}{l}\text { Other } \\
\text { transport }\end{array}$ & $\begin{array}{c}\text { Food and non- } \\
\text { alcoholic } \\
\text { beverages }\end{array}$ & $\begin{array}{c}\text { Alcoholic } \\
\text { beverages \& } \\
\text { tobacco }\end{array}$ & $\begin{array}{l}\text { Recreation } \\
\text { and culture }\end{array}$ & $\begin{array}{l}\text { Restaurants } \\
\text { and hotels }\end{array}$ & Education & Comms & Other \\
\hline Electricity & -0.39 & 0.10 & -0.08 & -0.06 & -0.08 & 0.02 & 0.03 & -0.01 & -0.01 & -0.01 & -0.01 & -0.01 \\
\hline \multirow[t]{2}{*}{ Gas } & & - & & & & & & & & & & \\
\hline & 0.07 & 0.59 & 0.36 & -0.05 & -0.06 & 0.02 & 0.02 & -0.01 & -0.01 & -0.01 & -0.01 & -0.01 \\
\hline Other & & & & & & & & & & & & - \\
\hline fuels & 0.04 & 0.12 & -0.76 & -0.02 & -0.02 & 0.01 & 0.01 & -0.004 & -0.003 & -0.003 & -0.003 & 0.004 \\
\hline $\begin{array}{l}\text { Vehicle } \\
\text { fuels }\end{array}$ & 0.07 & 0.15 & 0.16 & -0.59 & -0.001 & -0.01 & -0.01 & -0.03 & -0.02 & -0.02 & -0.02 & -0.03 \\
\hline
\end{tabular}




\subsection{Estimates of rebound effects}

The estimated rebound effects are presented in four ways to illustrate both their magnitude and their underlying drivers. Specifically, we indicate the relative contribution of: a) income and substitution effects; b) direct and indirect rebound effects; c) direct and embodied emissions; and d) individual commodities.

Our estimates of the total rebound effect are $63 \%$ for gas, $53 \%$ for electricity and $46 \%$ for vehicle fuels, (Figure 4). These estimates are larger than many in the literature, although smaller than those by Brannlund et al (2007) and Mizobuchi (2008). Net substitution across all commodities accounts for between two thirds and three quarters of the total rebound for electricity and gas, but only one fifth for vehicle fuels. This demonstrates the importance of capturing substitution effects and suggests that studies that only estimate income effects could underestimate the total rebound - particularly for electricity and gas.

Our estimates of direct rebound effects are $59 \%$ for vehicle fuels, $58 \%$ for gas and $41 \%$ for electricity (Figure 5) - indicating that they account for the majority of the total rebound. For vehicle fuels, the direct rebound effect exceeds the total rebound effect, since the indirect rebound effect is negative. These estimates are at the high end of the range in the literature, particularly for vehicle fuels where most (primarily US) studies estimate direct rebound effects of $20 \%$ or less (Sorrell and Dimitropoulos, 2007b). Figure 6 demonstrates that the income effects mostly derive from other commodities (indirect rebound) while the substitution effects mostly derive from the energy service itself (direct rebound). Again, studies that only estimate income effects could erroneously conclude that the indirect rebound effect accounts for the majority of the total rebound - whereas these results show the opposite. 
Direct emissions from energy commodities account for between two thirds and three quarters of the total rebound (Figure 7). This follows directly from the above, since it is the direct rebound effect that dominates the overall rebound effect and this is wholly direct emissions. Reduced consumption of other energy commodities slightly reduces the total rebound effect for electricity and gas but has a greater impact on the total rebound for vehicle fuels. Income effects are dominated by embodied emissions (i.e. non-energy commodities) while substitution effects are dominated by direct emissions (i.e. energy commodities) (Figure 8). Since the latter is larger than the former, substitution both within and between energy commodities have the dominant influence on the overall results. Again, studies that neglect substitution effects could erroneously conclude that the total rebound effect consists primarily of embodied emissions - whereas these results show the opposite.

Finally, Figure 9 illustrates the relative contribution of different commodities to the total rebound (normalised to 100\%). This again shows the dominance of own-price effects. Substitution between electricity and gas dampens the rebound effect for these two commodities, as does substitution away from food and beverages. In contrast, the complementary relationship between energy commodities and both 'other transport' and 'other goods and services' contributes a positive rebound effect. For vehicle fuels, substitution away from electricity and gas significantly reduces the total rebound. 
Figure 4 Estimated rebound effects - split by net income and substitution effects

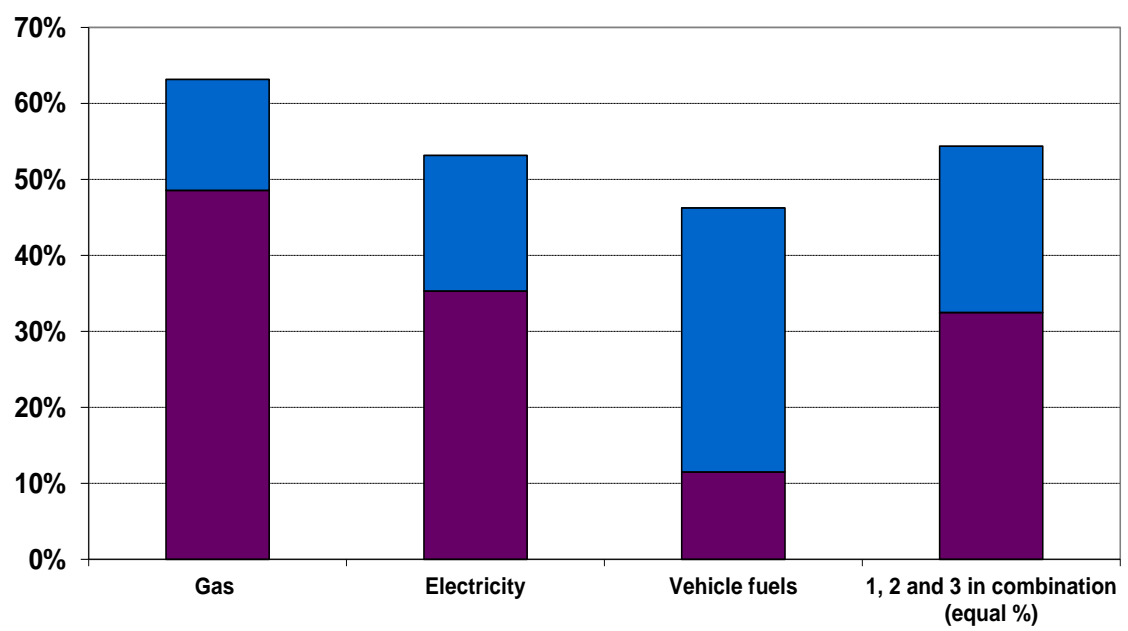

- Substitution effect $\quad$ Income effect

Figure 5 Estimated rebound effects - split by direct and indirect rebound effects

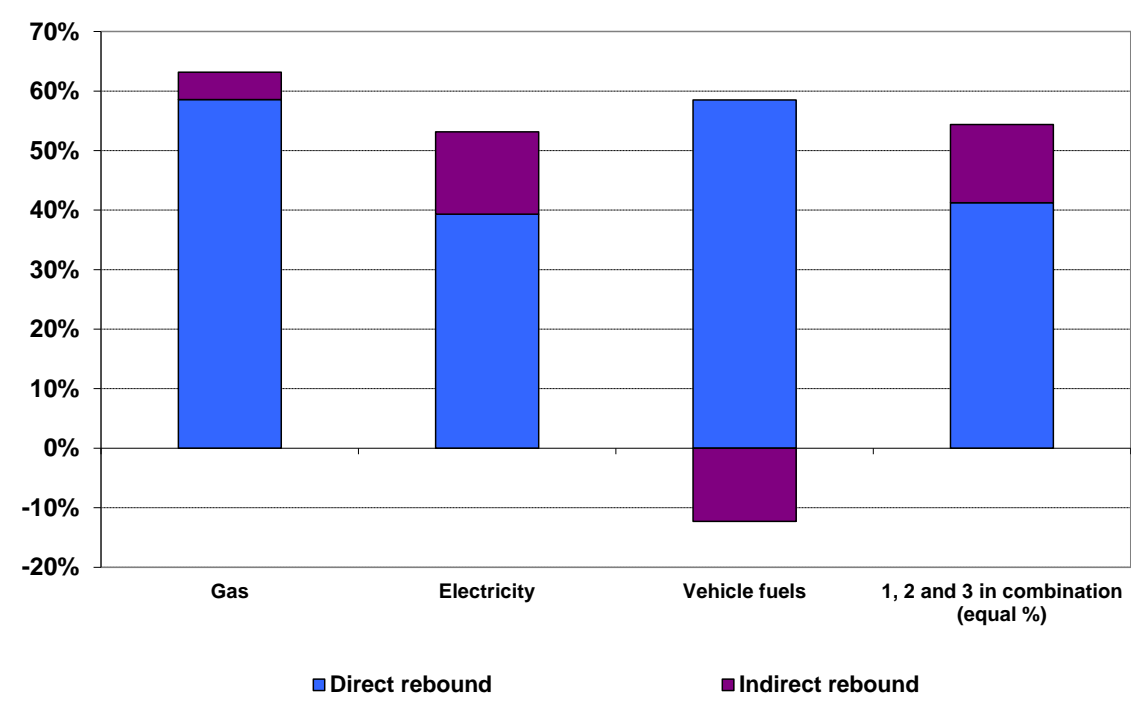


Figure 6 Net income and substitution effects - split by direct and indirect rebound

\section{Income effect}

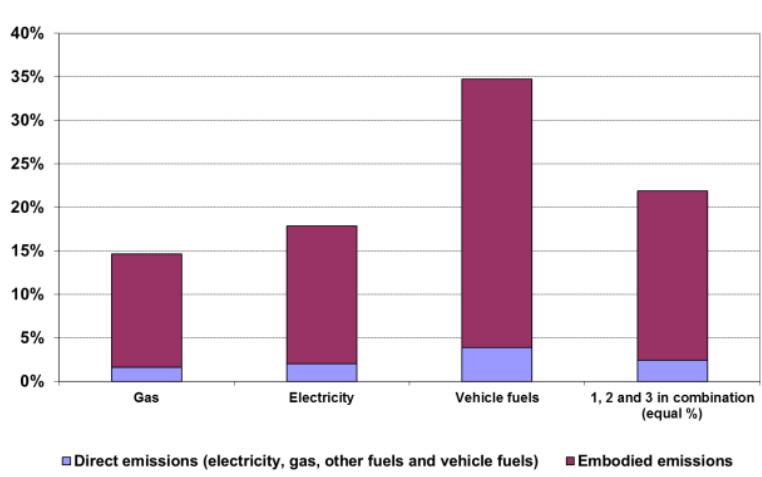

\section{Substitution effect}

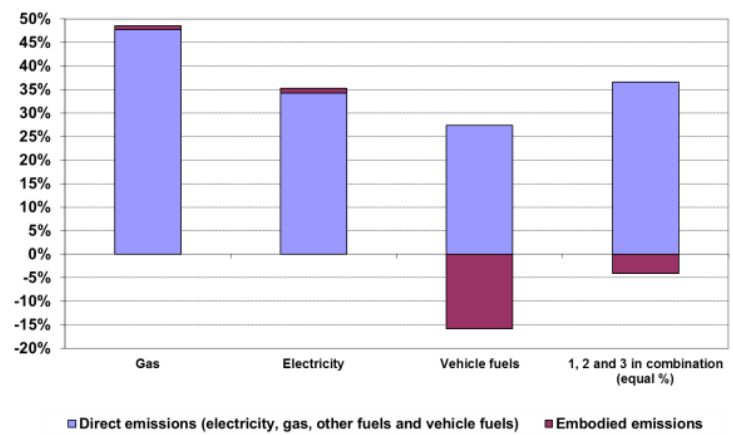

Figure 7 Estimated rebound effects - split by direct and embodied emissions

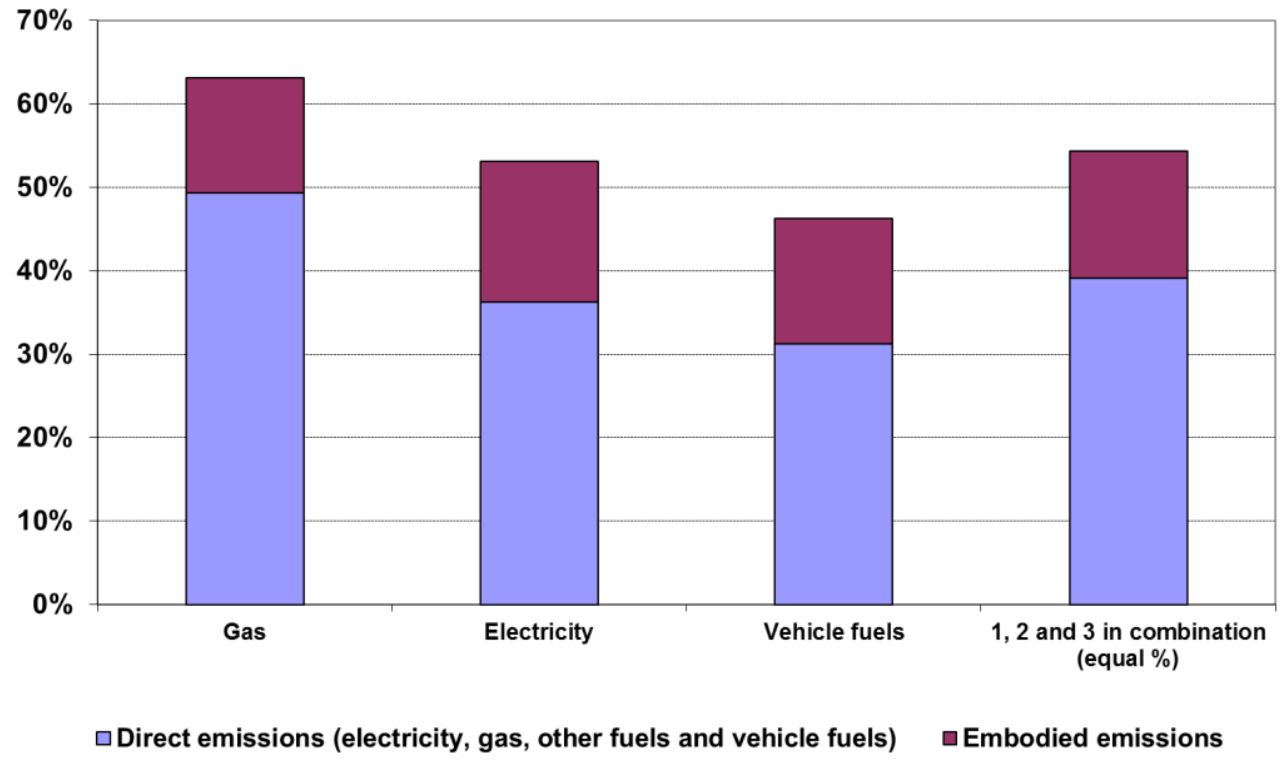


Figure 8 Net income and substitution rebound effects - split by direct and embodied emissions

\section{Income effect}

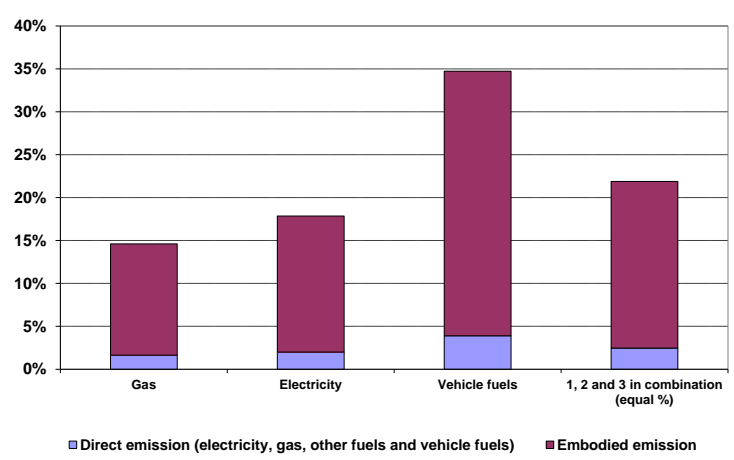

Substitution effect

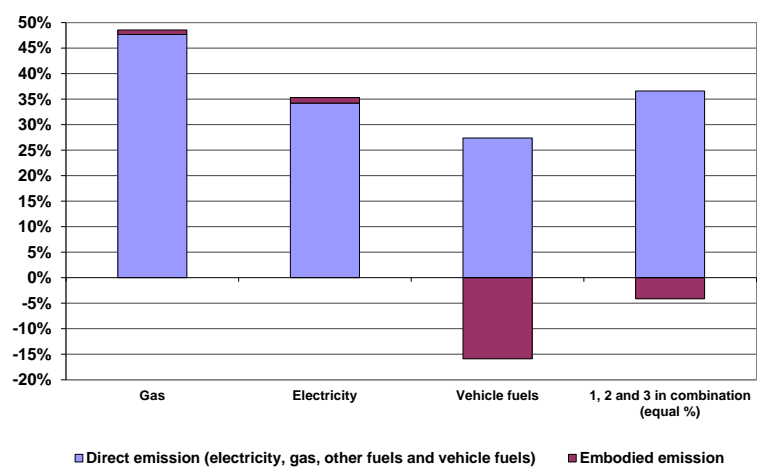

Figure 9 Contribution of different commodity groups to the total rebound effect

Gas

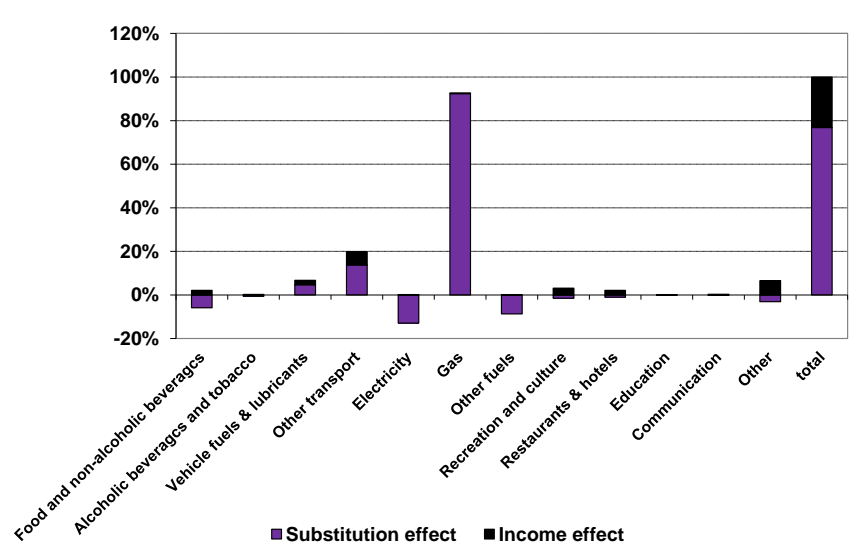

Electricity

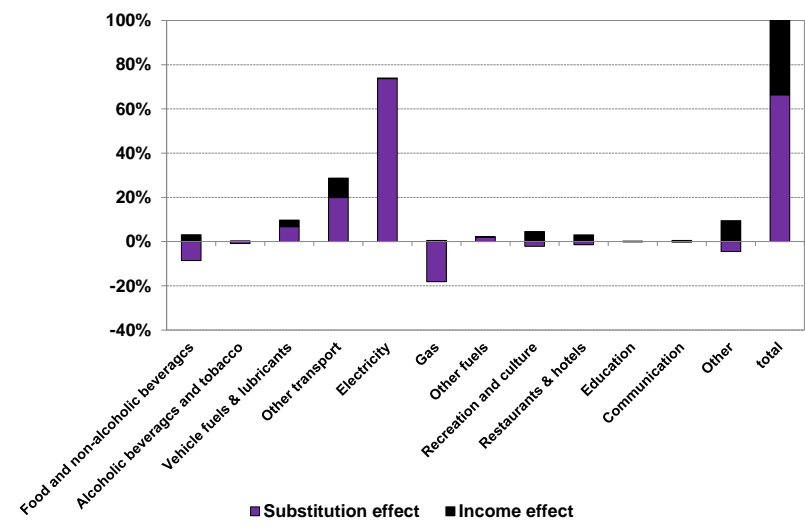


Vehicle fuels

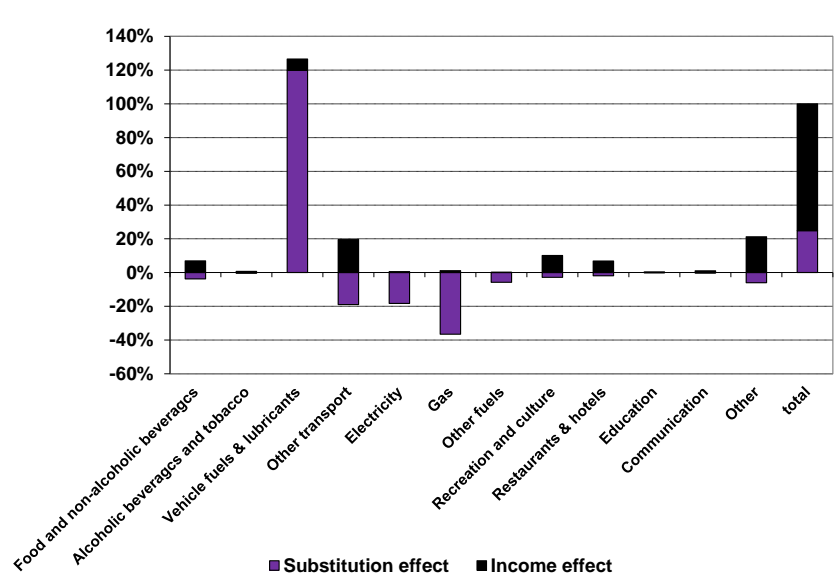

Combined

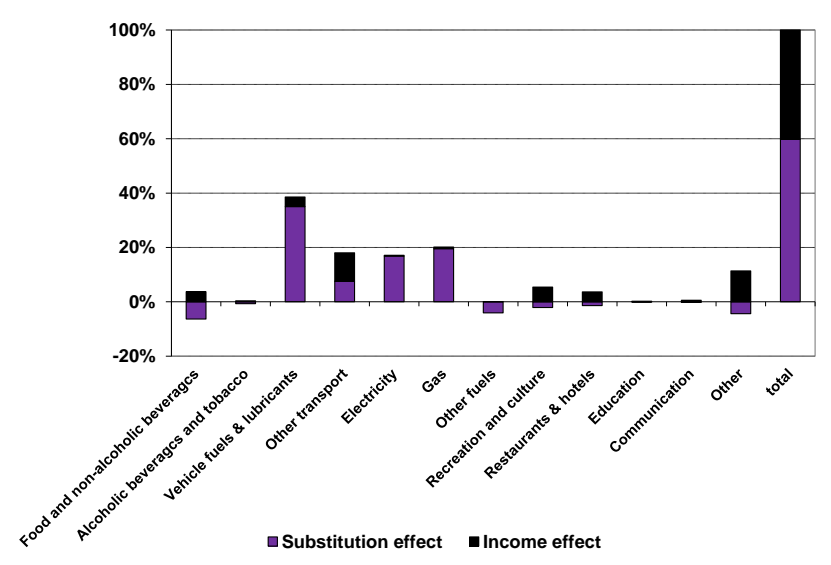

\section{Discussion}

In our previous study of combined direct and indirect rebound effects for UK households (Chitnis et al., 2014) we concluded that the total rebound effect was modest (0-32\%) for measures affecting domestic energy use and larger (25-65\%) for measures affecting vehicle fuels, and that it primarily derived from increased consumption of non-energy goods and services. We further suggested we may have underestimated the total rebound since we did not model substitution effects.

The present study shows that this suggestion was correct. By using price rather than expenditure elasticities, we now estimate significantly larger rebound effects, namely $63 \%$ for domestic gas use, $53 \%$ for electricity and $46 \%$ for vehicle fuels. The primary source of this rebound is increased consumption of cheaper energy services (i.e. direct rebound), and this is primarily driven by substitution effects. A clear implication of this finding is that studies that ignore substitution effects (e.g. those in Table 3) will underestimate the total rebound. 
In practice, many studies focus solely upon direct rebound effects and estimate these from time-series data on individual energy services (e.g. transport, heating). Since, by definition, these neglect indirect rebound effects, their results may also underestimate the total rebound (unless, that is, the indirect rebound effect is negative). However, our results suggest that such studies may provide a better approximation to the total rebound effect than do studies that estimate the latter using only expenditure elasticities. Since the direct rebound effect appears larger than the indirect rebound effect, errors in estimating the former will matter more than errors in estimating the latter.

We suspect, however, that the present study (along with others in Table 4) may overestimate the total rebound effect. The primary reason for this is that we assume the own-price elasticity of energy demand to be equivalent to the efficiency elasticity of energy service demand $\left(\eta_{q_{e}, \varepsilon}=\eta_{q_{e}, p_{e}}\right)$ and therefore to provide a suitable measure of the direct rebound effect. As Sorrell and Dimitropoulos (2007a) show, this equivalence only holds if energy prices are exogenous, energy service demand depends only on energy service prices $\left(p_{s}\right)$ and energy efficiency is constant. Absent these conditions, the own-price elasticity of energy demand will overestimate the direct rebound effect (Sorrell and Dimitropoulos, 2007a). Factors such as the endogeneity of energy efficiency and the asymmetric response of consumers to changes in energy prices may exacerbate this bias (Sorrell and Dimitropoulos, 2007a). Hence, the simplicity of using energy commodities rather than energy services in the demand model comes at a cost.

A further bias may arise when energy commodities provide multiple energy services (Chan and Gillingham, 2014). For example, if electric heating is a complement (substitute) to lighting, the own-price elasticity of electricity may overestimate (underestimate) the direct rebound effect for each. Hunt and Ryan (2014) explore this point by estimating a LAIDS 
model of household energy purchases that includes covariates that they assume to be correlated with energy efficiency. ${ }^{20}$ Although not equivalent to including energy services within the demand model, their approach leads to lower estimates of energy price elasticities than specifications in which these covariates are omitted. This further suggests that the specification used here may overestimate energy price elasticities and hence also the total rebound effect.

We further observe that our estimates of energy price elasticities are at the high end of the range found in the literature. Lower estimates of these elasticities would lead to lower estimates of the direct rebound effect - and correspondingly higher estimates of the indirect rebound effect. Since energy commodities are relatively GHG intensive, the former is likely to outweigh the latter leading to a lower estimate of the total rebound.

Further caveats relate to the methodological trade-offs discussed in section 2.3 - including the limited number of commodity groups employed, the potential sensitivity of the results to separability assumptions and the absence of socio-economic covariates. Our methodology also neglects any supply-side responses to improved energy efficiency which may modify the estimated effects. The likely direction of bias from these sources is ambiguous, although they all represent important avenues for future research. But the priority is to find ways of incorporating energy services directly within a household demand model.

\section{Summary}

This study adds to a small but growing volume of evidence that estimates combined direct and indirect rebound effects for households. We extend the existing literature by estimating a

\footnotetext{
${ }^{20}$. Hunt and Ryan try three approaches, namely: a simple time trend; historic energy prices; and historic energy prices allowing for asymmetric responses.
} 
full household demand model and identifying the relative contribution of different mechanisms to the results. Our results suggest a total rebound effect of $63 \%$ for measures affecting domestic gas use, $53 \%$ for measures affecting electricity use and $46 \%$ for measures affecting vehicle fuel use. The primary source of this rebound is increased consumption of cheaper energy services (i.e. direct rebound) and this in turn is primarily driven by substitution effects. Our results suggest that previous studies that neglected substitution effects may have underestimated the total rebound effect. However, we have identified a number of reasons why our estimates may be upwardly biased. To reduce this risk, future research should give priority to including energy services directly within a household demand model.

\section{Acknowledgments}

This research was supported by funding from the UK Department of Environment Food and Rural Affairs (DEFRA), the UK Economic and Social Research Council (ESRC) and the Scottish Government as part of the Sustainable Lifestyles Research Group (SLRG). Completion of the research was funded by the Research Councils UK through their support for the Centre on Innovation Energy Demand (Grant No. EP/KO11790/1). Earlier versions of this paper were presented at IAEE conferences in Düsseldorf (August 2013), New York (June 2014) and Rome (October 2014) and at a BIEE conference in Oxford (September 2014). The authors would like to thank Lester Hunt and Euan Phimister for invaluable discussions. The usual disclaimers apply. 


\section{Annex 1 - Parameter estimates and restrictions tests}

Table A.l Parameter estimates from first stage equations

\begin{tabular}{|c|c|c|c|c|c|c|c|c|c|c|}
\hline & \multirow[t]{2}{*}{$\alpha^{r}$} & \multirow[t]{2}{*}{$\beta^{r}$} & \multicolumn{4}{|c|}{$\gamma^{r s}$} & \multicolumn{3}{|c|}{$\lambda^{r s}$} & \multirow[t]{2}{*}{$\bar{R}^{2}$} \\
\hline & & & Energy & Transport & $\begin{array}{l}\text { Food and } \\
\text { beverages }\end{array}$ & $\begin{array}{c}\text { Other } \\
\text { goods and } \\
\text { services }^{2}\end{array}$ & Energy & Transport & $\begin{array}{l}\text { Food and } \\
\text { beverages }\end{array}$ & \\
\hline Energy & $\begin{array}{c}-0.02 \\
(-5.1)^{* *}\end{array}$ & $\begin{array}{c}-0.03 \\
(-6.6)^{* *}\end{array}$ & $\begin{array}{c}0.02 \\
(10.0)^{* *}\end{array}$ & $\begin{array}{c}0.01 \\
(3.0)^{* *}\end{array}$ & $\begin{array}{c}-0.03 \\
(-4.0)^{* *}\end{array}$ & -0.01 & $\begin{array}{c}0.13 \\
(1.6)^{*}\end{array}$ & $\begin{array}{c}0.06 \\
(2.1)^{* *}\end{array}$ & $\begin{array}{c}0.05 \\
(3.0)^{* *}\end{array}$ & 0.99 \\
\hline Transport & $\begin{array}{c}0.06 \\
(4.9)^{* *}\end{array}$ & $\begin{array}{c}0.04 \\
(2.8)^{* *}\end{array}$ & $\begin{array}{c}-0.02 \\
(-3.5)^{* *}\end{array}$ & $\begin{array}{c}0.06 \\
(5.2)^{* *}\end{array}$ & $\begin{array}{c}-0.03 \\
(-1.9)^{* *}\end{array}$ & -0.01 & $\begin{array}{c}0.83 \\
(4.4)^{* *}\end{array}$ & $\begin{array}{c}0.70 \\
(10.6)^{* *}\end{array}$ & $\begin{array}{l}-0.004 \\
(-0.1)\end{array}$ & 0.96 \\
\hline $\begin{array}{l}\text { Food and } \\
\text { beverages }\end{array}$ & $\begin{array}{l}0.01 \\
(0.5)\end{array}$ & $\begin{array}{c}-0.05 \\
(-3.4)^{* *}\end{array}$ & $\begin{array}{l}0.01 \\
(1.4)\end{array}$ & $\begin{array}{l}-0.02 \\
(-1.4)\end{array}$ & $\begin{array}{c}0.06 \\
(3.6)^{* *}\end{array}$ & -0.05 & $\begin{array}{c}-0.77 \\
(-4.2)^{* *}\end{array}$ & $\begin{array}{l}-0.07 \\
(-1.1)\end{array}$ & $\begin{array}{c}0.83 \\
(19.3)^{* *}\end{array}$ & 0.99 \\
\hline $\begin{array}{l}\text { Other goods } \\
\text { and } \\
\text { services }^{1}\end{array}$ & 0.96 & 0.05 & -0.01 & -0.06 & 0.001 & 0.07 & -0.19 & -0.69 & -0.88 & - \\
\hline
\end{tabular}

- $\quad \bar{R}^{2}$ is the adjusted coefficient of determination.

- $t$-values in parenthesis. $* *$ and $*$ indicate statistical significance at $5 \%$ and $10 \%$ probability levels respectively.

- Coefficients for 'other goods \& services' are estimated from the adding-up and homogeneity restrictions.

- The lagged budget share of 'other goods \& services' is dropped to avoid co-linearity. 
Table A.2 Parameter estimates from second stage equations - energy group

\begin{tabular}{|c|c|c|c|c|c|c|c|c|}
\hline & \multirow[t]{2}{*}{$\alpha_{i}^{r}$} & \multirow[t]{2}{*}{$\beta_{i}^{r}$} & \multicolumn{3}{|c|}{$\gamma_{i j}^{r}$} & \multicolumn{2}{|c|}{$\lambda_{i j}^{r}$} & \multirow[t]{2}{*}{$\bar{R}^{2}$} \\
\hline & & & Electricity & Gas & Other fuels $^{1}$ & Electricity & Gas & \\
\hline \multirow[t]{2}{*}{ Electricity } & -0.65 & -0.19 & 0.11 & -0.11 & -0.04 & 0.56 & 0.34 & 0.91 \\
\hline & $(-3.6) * *$ & $(-4.6) * *$ & $(6.1)^{* *}$ & $(-6.0)^{* *}$ & $(-2.8) * *$ & $(6.8)^{* *}$ & $(5.0)^{* *}$ & \\
\hline \multirow[t]{2}{*}{ Gas } & 0.50 & 0.13 & -0.06 & 0.08 & 0.01 & 0.20 & 0.62 & 0.98 \\
\hline & $(2.8)^{* *}$ & $(3.0)^{* *}$ & $(-3.3)^{* *}$ & $(4.4)^{* *}$ & (1.0) & $(2.3)^{* *}$ & $(8.8)^{* *}$ & \\
\hline Other fuels $^{1}$ & 1.15 & 0.06 & -0.05 & 0.03 & 0.02 & -0.76 & -0.96 & - \\
\hline
\end{tabular}

Notes:

- Coefficients for 'other goods \& services' are estimated from the adding-up restriction.

- The lagged budget share of 'other goods \& services' is dropped to avoid co-linearity.

Table A.3 Parameter estimates from second stage equations - transport group

\begin{tabular}{lcccccc} 
& $\alpha_{i}^{r}$ & $\beta_{i}^{r}$ & & $\gamma_{i j}^{r}$ & $\lambda_{i j}^{r}$ & $\bar{R}^{2}$ \\
& & & Vehicle & Other & Vehicle & \\
& & & fuels & transport $^{2}$ & fuels & \\
\hline Vehicle & -0.003 & -0.04 & 0.07 & -0.07 & 0.46 & 0.74 \\
fuels & $(-0.2)$ & $(-5.5)^{* *}$ & $(5.1)^{* *}$ & $(-5.1)^{* *}$ & $(5.4)^{* *}$ & \\
\hline Other & 1.00 & 0.04 & -0.07 & 0.07 & -0.46 & - \\
transport & & & & & & \\
\hline
\end{tabular}

Notes:

- Coefficients for 'other transport' are estimated from the adding-up and homogeneity restrictions.

- The lagged budget share of 'other transport' is dropped to avoid co-linearity. 
Table A.4 Parameter estimates from second stage equations - food and beverages group

\begin{tabular}{|c|c|c|c|c|c|c|}
\hline & $\alpha_{i}^{r}$ & $\beta_{i}^{r}$ & \multicolumn{2}{|c|}{$\gamma_{i j}^{r}$} & $\lambda_{i j}^{r}$ & $\bar{R}^{2}$ \\
\hline & & & $\begin{array}{l}\text { Food and } \\
\text { non- } \\
\text { alcoholic } \\
\text { beverages }\end{array}$ & $\begin{array}{c}\text { Alcoholic } \\
\text { beverages } \\
\text { and } \\
\text { tobacco }^{2}\end{array}$ & $\begin{array}{l}\text { Food and } \\
\text { non- } \\
\text { alcoholic } \\
\text { beverages }\end{array}$ & \\
\hline $\begin{array}{l}\text { Food and } \\
\text { non-alcoholic } \\
\text { beverages }\end{array}$ & $\begin{array}{c}0.16 \\
(2.6)^{* *}\end{array}$ & $\begin{array}{l}-0.05 \\
(-1.5)\end{array}$ & $\begin{array}{c}0.03 \\
(2.6)^{* *}\end{array}$ & $\begin{array}{c}-0.03 \\
(-2.6)^{* *}\end{array}$ & $\begin{array}{c}0.58 \\
(3.9)^{* *}\end{array}$ & 0.91 \\
\hline $\begin{array}{l}\text { Alcoholic } \\
\text { beverages } \\
\text { and tobacco }\end{array}$ & 0.84 & 0.05 & -0.03 & 0.03 & -0.58 & - \\
\hline
\end{tabular}

Notes:

- Coefficients for 'alcoholic beverages and tobacco' are estimated from the adding-up and homogeneity restrictions.

- The lagged budget share of 'alcoholic beverages and tobacco' is dropped to avoid co-linearity. 
Table A.5 Parameter estimates from second stage equations - other goods and services group

\begin{tabular}{|c|c|c|c|c|c|c|c|c|c|c|c|c|}
\hline & $\alpha_{i}^{r}$ & $\beta_{i}^{r}$ & & & $\gamma_{i j}^{r}$ & & & & & $\lambda_{i j}^{r}$ & & $\bar{R}^{2}$ \\
\hline & & & $\begin{array}{l}\text { Recreation } \\
\& \text { culture }\end{array}$ & $\begin{array}{c}\text { Restaurants } \\
\& \text { hotels }\end{array}$ & Education & Communication & Other & $\begin{array}{l}\text { Recreation } \\
\& \text { culture }\end{array}$ & $\begin{array}{c}\text { Restaurants } \\
\& \text { hotels }\end{array}$ & Education & Communication & \\
\hline $\begin{array}{l}\text { Recreation \& } \\
\text { culture }\end{array}$ & $\begin{array}{c}0.06 \\
(2.7)^{* *}\end{array}$ & $\begin{array}{c}0.02 \\
(3.1)^{* *}\end{array}$ & $\begin{array}{c}0.07 \\
(5.6)^{* *}\end{array}$ & $\begin{array}{c}-0.03 \\
(-3.3)^{* *}\end{array}$ & $\begin{array}{c}0.03 \\
(4.2)^{* *}\end{array}$ & $\begin{array}{c}-0.03 \\
(-5.0)^{* *}\end{array}$ & -0.32 & $\begin{array}{c}0.67 \\
(10.0)^{* *}\end{array}$ & $\begin{array}{l}0.07 \\
(0.7)\end{array}$ & $\begin{array}{l}-0.01 \\
(-0.1)\end{array}$ & $\begin{array}{c}0.46 \\
(2.6)^{* *}\end{array}$ & 0.90 \\
\hline $\begin{array}{l}\text { Restaurants \& } \\
\text { hotels }\end{array}$ & $\begin{array}{c}0.11 \\
(3.8)^{* *}\end{array}$ & $\begin{array}{l}0.01 \\
(1.2)\end{array}$ & $\begin{array}{c}0.03 \\
(1.7)^{*}\end{array}$ & $\begin{array}{l}-0.001 \\
(-0.1)\end{array}$ & $\begin{array}{l}0.01 \\
(0.6)\end{array}$ & $\begin{array}{l}0.001 \\
(0.1)\end{array}$ & -0.26 & $\begin{array}{l}-0.1 \\
(-1.0)\end{array}$ & $\begin{array}{c}0.40 \\
(2.3)^{* *}\end{array}$ & $\begin{array}{l}-0.30 \\
(-1.3)\end{array}$ & $\begin{array}{l}0.22 \\
(0.9)\end{array}$ & 0.94 \\
\hline Education & $\begin{array}{c}-0.01 \\
(-1.7)^{*}\end{array}$ & $\begin{array}{l}0.002 \\
(1.1)\end{array}$ & $\begin{array}{c}-0.01 \\
(-1.6)^{*}\end{array}$ & $\begin{array}{l}-0.002 \\
(-0.6)\end{array}$ & $\begin{array}{c}0.004 \\
(1.9)^{* *}\end{array}$ & $\begin{array}{c}0.01 \\
(3.0)^{* *}\end{array}$ & -0.27 & $\begin{array}{l}0.02 \\
(1.3)\end{array}$ & $\begin{array}{c}0.12 \\
(4.6)^{* *}\end{array}$ & $\begin{array}{c}1.05 \\
(22.0)^{* *}\end{array}$ & $\begin{array}{c}-0.26 \\
(-5.0)^{* *}\end{array}$ & 0.98 \\
\hline Communication & $\begin{array}{c}-0.02 \\
(- \\
2.1)^{* *}\end{array}$ & $\begin{array}{c}- \\
0.0003 \\
(-0.1)\end{array}$ & $\begin{array}{c}-0.02 \\
(-4.8)^{* *}\end{array}$ & $\begin{array}{c}0.01 \\
(3.3)^{* *}\end{array}$ & $\begin{array}{c}-0.01 \\
(-2.5)^{* *}\end{array}$ & $\begin{array}{c}0.02 \\
(7.4)^{* *}\end{array}$ & -0.05 & $\begin{array}{c}0.18 \\
(7.2)^{* *}\end{array}$ & $\begin{array}{l}-0.01 \\
(-0.4)\end{array}$ & $\begin{array}{c}0.27 \\
(4.4)^{* *}\end{array}$ & $\begin{array}{c}0.45 \\
(6.8)^{* *}\end{array}$ & 0.97 \\
\hline Other & 0.85 & -0.04 & -0.10 & 0.04 & -0.05 & 0.02 & -0.84 & -0.80 & -0.58 & -1.00 & -0.87 & - \\
\hline
\end{tabular}

- Coefficients for 'other' are estimated from the adding-up and homogeneity restrictions.

- The lagged budget share of 'other' is dropped to avoid co-linearity. 
Table A.6 Results of Wald test for symmetry and homogeneity restrictions

\begin{tabular}{lccccc}
\hline Restriction & $\begin{array}{c}\text { Aggregate } \\
\text { groups }\end{array}$ & $\begin{array}{c}\text { Food and } \\
\text { beverages }\end{array}$ & Transport & Energy & $\begin{array}{c}\text { Other goods } \\
\text { and services }\end{array}$ \\
\hline Symmetry & $33.5^{*}$ & & 2.7 & $27.8^{*}$ & $41.4^{*}$ \\
\hline Homogeneity & 5.7 & 1.2 & $27.8^{*}$ & $58.3^{*}$ \\
\hline $\begin{array}{l}\text { Symmetry and } \\
\text { homogeneity }\end{array}$ & $45.4^{*}$ & & & \\
combined & & & & $53.2^{*}$ \\
\hline $\begin{array}{l}\text { Symmetry } \\
\text { with }\end{array}$ & $39.0^{*}$ & & & \\
homogeneity & & & & \\
imposed & & & & \\
\hline Notes: & & & & \\
\hline
\end{tabular}

- The restriction is the null hypothesis. * indicates that rejection of the null hypothesis significant at the $5 \%$ level.

- Symmetry tests not feasible for food and beverages and transport since there are only two equations in each group and one is dropped to satisfy adding up. 


\section{Annex 2 - Between-group elasticity estimates}

Table A.7 Between-group expenditure elasticities $\left(\eta_{q_{r} x}\right)$

\begin{tabular}{lc}
\hline & Expenditure elasticity \\
\hline Energy & 0.11 \\
\hline Transport & 1.26 \\
\hline Food and beverages & 0.75 \\
\hline Other goods and services & 1.07 \\
\hline
\end{tabular}

Table A.8 Between-group compensated price elasticities $\left(\tilde{\eta}_{q_{r} p_{s}}\right)$

\begin{tabular}{|c|c|c|c|c|}
\hline & Energy & Transport & Food and beverages & Other goods and services \\
\hline Energy & -0.34 & -0.11 & 0.08 & 0.04 \\
\hline Transport & 0.51 & -0.42 & 0.06 & 0.04 \\
\hline Food and beverages & -0.52 & -0.04 & -0.50 & 0.20 \\
\hline Other goods and services & 0.35 & 0.57 & 0.37 & -0.26 \\
\hline
\end{tabular}


Table A.9 Between-group uncompensated price elasticities $\left(\eta_{q_{r} p_{s}}\right)$

\begin{tabular}{lcccc}
\hline & Energy & Transport & Food and beverages & Other goods and services \\
\hline Energy & -0.34 & -0.16 & 0.05 & -0.02 \\
\hline Transport & 0.50 & -0.59 & -0.05 & -0.10 \\
\hline Food and beverages & -0.54 & -0.29 & -0.65 & -0.01 \\
\hline Other goods and services & 0.27 & -0.23 & -0.11 & -0.93 \\
\hline
\end{tabular}


Annex 3 - Within-group elasticity estimates for domestic energy and vehicle fuels

Table A.10 Within-group expenditure elasticities $\left(\eta_{q_{i} x_{r}}^{r}\right)$

\begin{tabular}{lcc}
\hline & Energy & Transport \\
\hline Electricity & 0.61 & - \\
\hline Gas & 1.35 & - \\
\hline Other fuels & 1.44 & - \\
\hline Vehicle fuels & - & 0.80 \\
\hline
\end{tabular}

Table A.11 Within-group compensated price elasticities $\left(\tilde{\eta}_{q_{i} p_{j}}^{r}\right)$

\begin{tabular}{|c|c|c|c|c|c|}
\hline & \multicolumn{3}{|c|}{ Energy } & \multicolumn{2}{|c|}{ Transport } \\
\hline & Electricity & Gas & Other fuels & Vehicle fuels & Other transport \\
\hline Electricity & -0.29 & 0.33 & 0.16 & - & - \\
\hline Gas & 0.15 & -0.42 & 0.54 & - & - \\
\hline Other fuels & 0.07 & 0.18 & -0.69 & - & - \\
\hline Vehicle fuels & - & - & & -0.48 & 0.14 \\
\hline
\end{tabular}


Table A.12 Within-group uncompensated price elasticities $\left(\eta_{q_{i} p_{j}}^{r}\right)$

\begin{tabular}{cccccc}
\hline & \multicolumn{3}{c}{ Energy } & \multicolumn{2}{c}{ Transport } \\
\hline & Electricity & Gas & Other fuels & Vehicle fuels & Other transport \\
\hline Electricity & -0.59 & -0.33 & -0.55 & - & - \\
\hline Gas & -0.07 & -0.91 & 0.02 & - & - \\
\hline Other fuels & -0.02 & -0.01 & -0.90 & - & - \\
\hline Vehicle fuels & - & - & & -0.66 & -0.10 \\
\hline
\end{tabular}




\section{References}

Alfredsson, E.C., 2004. 'Green' consumption - no solution for climate change. Energy 29, 513-524.

Asche, F., Nilsen, O.B., Tveterås, R., 2008. Natural gas demand in the European household sector. The Energy Journal, 27-46.

Brannlund, R., Ghalwash, T., Nordstrom, J., 2007. Increased energy efficiency and the rebound effect: effects on consumption and emissions. Energy Economics 29, 1-17.

Buse, A., 1994. Evaluating the linearized almost ideal demand system. American Journal of Agricultural Economics 76, 781-793.

Chan, N., Gillingham, K., 2014. The Microeconomic Theory of the Rebound Effect and its Welfare Implications. Journal of the Association of Environmental and Resource Economists.

Chitnis, M., Sorrell, S., Druckman, A., Firth, S.K., Jackson, T., 2013. Turning lights into flights: Estimating direct and indirect rebound effects for UK households. Energy Policy $55,234-250$.

Chitnis, M., Sorrell, S., Druckman, A., Firth, S.K., Jackson, T., 2014. Who rebounds most? Estimating direct and indirect rebound effects for different UK socioeconomic groups. Ecological Economics 106, 12-32.

Conrad, K., Schröder, M., 1991. Demand for Durable and Nondurable Goods, Environmental Policy and Consumer Welfare. Journal of Applied Econometrics 6, 271-286.

Deaton, A., Muellbaeur, J., 1980. Economics and Consumer Behaviour. Cambridge University Press.

Deaton, A., Muellbauer, J., 1980. An Almost Ideal Demand System. The American Economic Review 70, 312-326.

DGLC, 2014. Live tables on househhold projections. UK Department of Communities and Local Government, London.

Druckman, A., Chitnis, M., Sorrell, S., Jackson, T., 2011a. Missing carbon reductions: exploring rebound and backfire effects in UK households. Energy Policy 39, 3572-3581.

Druckman, A., Chitnis, M., Sorrell, S., Jackson, T., 2011b. Missing carbon reductions? Exploring rebound and backfire effects in UK households. Energy Policy 39, 3572-3581. 
Druckman, A., Jackson, T., 2008. Household energy consumption in the UK: A highly geographically and socio-economically disaggregated model. Energy Policy 36, 31773192.

Druckman, A., Jackson, T., 2009. The carbon footprint of UK households 1990-2004: A socio-economically disaggregated, quasi-multi-regional input-output model. Ecological Economics 68, 2066-2077.

Edgerton, D.L., 1997. Weak separability and the estimation of elasticities in multistage demand systems. American Journal of Agricultural Economics 79, 62-79.

Espey, J.A., Espey, M., 2004. Turning on the lights: A meta-analysis of residential electricity demand elasticities. Journal of Agricultural and Applied Economics 36, 65-82.

Goddard, D., 1983. An analysis of Canadian aggregate demand for food at home and away from home. Canadian Journal of Agricultural Economics/Revue canadienne d'agroeconomie 31, 289-318.

Goodwin, P., Dargay, J., Hanly, M., 2004. Elasticities of Road Traffic and Fuel Consumption with Respect to Price and Income: A Review. Transport Reviews 24, 275-292.

Hunt, L.C., Ryan, D.L., 2014. Catching on the Rebound: Why Price Elasticities are Generally Inappropriate Measures of Rebound Effects. School of Economics, University of Surrey.

Keuzenkamp, H.A., Barten, A.P., 1995. Rejection without falsification on the history of testing the homogeneity condition in the theory of consumer demand. Journal of Econometrics 67, 103-127.

Klonaris, S., Hallam, D., 2003. Conditional and unconditional food demand elasticities in a dynamic multistage demand system. Applied Economics 35, 503-514.

Kratena, K., Wuger, M., 2008. The full impact of energy efficiency on household's energy demand. Austrian Institute of Economic Research (WIFO).

Lenzen, M., Dey, C.J., 2002. Economic, energy and greenhouse emissions impacts of some consumer choice, technology and government outlay options. Energy Economics 24, 377403.

Lin, B., Liu, X., 2013. Reform of refined oil product pricing mechanism and energy rebound effect for passenger transportation in China. Energy Policy 57, 329-337.

Mizobuchi, K., 2008. An empirical study on the rebound effect considering capital costs. Energy Economics 30, 2486-2516.

Murray, C.K., 2013. What if consumers decided to all 'go green'? Environmental rebound effects from consumption decisions. Energy Policy 54, 240-256. 
ONS, 2010. Timeseries data for the UK National Accounts. UK Office of National Statistics, London.

ONS, 2011. Time-series data for the UK National Accounts. UK Office of National Statistics, London.

Ray, R., 1983. Estimating dynamic demand systems: Some results on pooled Indian budget data. Economics Letters 13, 291-296.

Ryan, D., Plourde, A., 2009. Empirical modelling of energy demand, in: Evans, J., Hunt, L.C. (Eds.), International Handbook on the Economics of Energy. Edward Elgar, Cheltenham, UK.

Shukur, G., 2002. Dynamic specification and misspecification in systems of demand equations: a testing strategy for model selection. Applied Economics 34, 709-725.

Small, K., Van Dender, K., 2007. Fuel efficiency motor vehicle travel: the declining rebound effect. The Energy Journal 28, 25-51.

Sorrell, S., 2007. The Rebound Effect: an assessment of the evidence for economy-wide energy savings from improved energy efficiency. UK Energy Research Centre, London.

Sorrell, S., 2010. Mapping rebound effects from sustainable behaviours: key concepts and literature review. Sustainable Lifestyles Research Group, University of Surrey.

Sorrell, S., Dimitropoulos, J., 2007a. The rebound effect: Microeconomic definitions, limitations and extensions. Ecological Economics 65, 636-649.

Sorrell, S., Dimitropoulos, J., 2007b. UKERC Review of evidence for the rebound effect: Technical Report 2: Econometric studies. UK Energy Research Centre, London.

Sorrell, S., Dimitropoulos, J., Sommerville, M., 2009. Empirical estimates of direct rebound effects: a review. Energ Policy 37, 1356-1371.

Thomas, B.A., Azevedo, I.L., 2013. Estimating direct and indirect rebound effects for U.S. households with input-output analysis. Part 2: Simulation. Ecological Economics 86, 188198.

Turner, K., Lenzen, M., Wiedmann, T., Barrett, J., 2007. Examining the global environmental impact of regional consumption activities - Part 1: A technical note on combining inputoutput and ecological footprint analysis. Ecological Economics 62, 37-44.

Wiedmann, T., Lenzen, M., Turner, K., Barrett, J., 2007. Examining the global environmental impact of regional consumption activities - Part 2: Review of input-output models for the assessment of environmental impacts embodied in trade. Ecological Economics 61, 15-26. 